\title{
Age-Related Vascular Pathology in Transgenic Mice Expressing Presenilin 1-Associated Familial Alzheimer's Disease Mutations
}

\author{
Miguel A. Gama Sosa, ${ }^{, \dagger}$ Rita De Gasperi, ${ }^{, \dagger}$ \\ Anne B. Rocher, ${ }^{\ddagger \S}$ Athena Ching-Jung Wang, ${ }^{\ddagger}$ \\ William G.M. Janssen, ${ }^{\ddagger}$ Tony Flores, ${ }^{\ddagger}$ \\ Gissel M. Perez, ${ }^{\star \dagger}$ James Schmeidler, ${ }^{\dagger}$ \\ Dara L. Dickstein, ${ }^{\ddagger \pi}$ Patrick R. Hof, ${ }^{\neq \mp \|}$ \\ and Gregory A. Elder ${ }^{\dagger * \star \dagger \dagger}$ \\ From the Research and Development* and Neurology Services,** \\ James J. Peters Department of Veterans Affairs Medical Center, \\ Bronx, New York; the Departments of Psychiatry, ${ }^{\dagger}$ Neuroscience, ${ }^{\neq}$ \\ Geriatrics and Palliative Care," and Neurology," and the

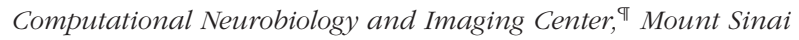 \\ School of Medicine, New York, New York; and the Department of \\ Anatomy and Neurobiology, ${ }^{\S}$ Boston University, \\ Boston, Massachusetts
}

Mutations in the presenilin 1 (PS1) gene are the most commonly recognized cause of familial Alzheimer's disease (FAD). Besides senile plaques, neurofibrillary tangles, and neuronal loss, Alzheimer's disease (AD) is also accompanied by vascular pathology. Here we describe an age-related vascular pathology in two lines of PS1 FAD-mutant transgenic mice that mimics many features of the vascular pathology seen in AD. The pathology was especially prominent in the microvasculature whose vessels became thinned and irregular with the appearance of many abnormally looped vessels as well as string vessels. Stereologic assessments revealed a reduction of the microvasculature in the hippocampus that was accompanied by hippocampal atrophy. The vascular changes were not congophilic. Yet, despite the lack of congophilia, penetrating vessels at the cortical surface were often abnormal morphologically and microhemorrhages sometimes occurred. Altered immunostaining of blood vessels with basement membraneassociated antigens was an early feature of the microangiopathy and was associated with thickening of the vascular basal laminae and endothelial cell alterations that were visible ultrastructurally. Interestingly, although the FAD-mutant transgene was expressed in neurons in both lines of mice, there was no detectable expression in vascular endothelial cells or glial cells. These studies thus have implications for the role of neuronal to vascular signaling in the pathogenesis of the vascular pathology associated with AD. (Am J Pathol 2010, 176:353-368; DOI: 10.2353/ajpath.2010.090482)

Whereas most cases of Alzheimer's disease (AD) occur sporadically, some are inherited in an autosomal dominant pattern and known as familial AD (FAD). These cases mimic the sporadic disease clinically and pathologically except for a typically earlier age of onset. Mutations in three genes, the amyloid precursor protein (APP), presenilin $1(P S 1)$, and presenilin $2(P S 2)$ are known to cause FAD, ${ }^{1}$ with mutations in PS1 being the most commonly recognized cause of early onset cases. ${ }^{2}$

In addition to senile plaques, neurofibrillary tangles, and neuron and synapse loss, AD is also accompanied by vascular pathology. In the most recognized form of this pathology, congophilic amyloid angiopathy (CAA), amyloid is deposited in the walls of blood vessels with leptomeningeal and neocortical arteries and arterioles being most affected., ${ }^{3,4}$ Vascular pathology, however, also occurs in the microvasculature leading to a decreased density and fragmentation of microvasculature. ${ }^{5}$ Microvessels appear less branched and thin atrophic vessels, known as string vessels, appear while other vessels become kinked and looped. The cause and relationship of microvascular pathology to cognitive decline in $A D$ remains unclear although patients with Down syndrome display a similar vascular pathology that is present in young cases devoid of senile plaques and neurofibril-

Supported by the National Institute on Aging (grants AG20139, AG02219, AG05138, AG010491, and AG029361), the Alzheimer's Association (IIRG-07-57318), and a merit award from the Department of Veterans Affairs (5I01BX000342-02).

Accepted for publication September 18, 2009.

Address correspondence and reprint requests to Gregory A. Elder, M.D., James J. Peters Veterans Affairs Medical Center, Neurology Service (3E16), 130 West Kingsbridge Road, Bronx, NY 10468. E-mail: gregory. elder@mssm.edu. 
lary tangles ${ }^{6}$ arguing that vascular changes may precede the development of neurofibrillary tangles and senile plaques. Vascular pathology also occurs in human PS1and PS2-associated FAD cases seeming to in general mimic the pathology found in sporadic cases. ${ }^{2}$

Despite the relative rarity of human FAD cases, their known genetic etiology makes them ideal for modeling in transgenic animals, and many FAD-mutant lines exist. Congophilic vascular deposits have been described in APP or APP/PS FAD-mutant mice..$^{7-12}$ There has been no description of vascular pathology in models expressing PS1 FAD mutants alone. Here we describe a microvascular pathology in two lines of PS1 FAD-mutant transgenic mice. Although the pathology lacks CAA, it mimics many of the other features of AD-related vascular pathology. In both lines, even though the mutant transgene was expressed in neurons, no detectable expression was found in vascular endothelial cells or glial cells suggesting a role for neuronal to vascular signaling in the pathology development.

\section{Materials and Methods}

\section{Genetically Modified Mice}

Transgenic mice expressing a wild-type human PS1 CDNA or a CDNA containing the P117L FAD mutation under the control of the neuron-specific enolase (NSE) promoter were generated by pronuclear injection and have been previously described (Table 1). ${ }^{13,14}$ These mice were generated on the C57BL/6 $\times \mathrm{DBA}_{1}$ hybrid background and have been maintained by breeding to C57BL/6 mice. Genotyping was performed as described previously. ${ }^{14}$
Transgenic mice expressing wild-type human PS1 from a P1 bacteriophage artificial chromosome (PAC) were produced using the clone RP1-54D12 (204 kb; accession number AC 006342) containing the entire human PS1 transcription unit $\left(>75 \mathrm{~kb} ;{ }^{15}\right)$. Founders were generated by injecting C57BL/6 $\times \mathrm{C}_{3} \mathrm{H} \mathrm{F}_{1}$ oocytes as described previously. ${ }^{16}$

To generate PAC transgenic mice expressing the M146V FAD mutation, the 54D12 clone was retrofitted using the Rec A-mediated homologous recombination system described by Ali Imam et al. ${ }^{17}$ A 1.6-kb fragment (nucleotides 135,630-137,240) containing PS1 exon 6 was amplified from PAC 54D12 DNA by PCR using the primer pair 5'-GGAGACCAAGGTGGGCAGAT-3' and 5'TGGAGCCCTAGCCTTCATTCT-3' and subcloned into the pCR2.1 vector (Invitrogen, Carlsbad, CA). The M146V FAD mutation (ATG to GTG codon change) was introduced by mutating the A residue at position 136,459 in the 54D12 clone (corresponding to nucleotide 653 of the PS1 mRNA) to G using the Quikchange kit (Stratagene, La Jolla, CA) and the complementary mutagenic primer set 5'-CCAGGAGGATAGTCACGACAACAATGACACT-3' and 5'-AGTGTCATTGTTGTCGTGAGCGGATAACAATTTCAC- $3^{\prime}$. The presence of the M146V mutation was identified by nucleotide sequence analyses.

The M146V mutation was introduced into the 54D12 PAC clone by homologous recombination using the pDF26 vector (gift from Drs. A. M. Ali Imam and F. Grosveld, Erasmus University, Rotterdam, The Netherlands). This vector harbors the chloramphenicol resistance gene $\left(\mathrm{Cm}^{\mathrm{R}}\right)$, an $\mathrm{rpsL}^{+}$allele for counter selection $\left(\mathrm{Stp}^{\mathrm{S}}\right)$, a temperature-sensitive replication initiation protein (RepAts), an origin of replication and the recA gene of Escherichia coli. The mutant 1.6-kb fragment was excised

Table 1. Groups of Mice Studied

\begin{tabular}{|c|c|c|c|}
\hline Strain & Transgene & Ages studied & Pathology observed \\
\hline PS1 PAC wild-type Tg & $\begin{array}{l}\text { P1 bacteriophage artificial chromosome } \\
\text { containing human PS1 }\end{array}$ & 4 to 28 months & None \\
\hline PS1 PAC M146V Tg & $\begin{array}{l}\text { P1 bacteriophage artificial chromosome } \\
\text { containing human PS1 retrofitted with } \\
\text { M146V FAD mutation }\end{array}$ & 4 to 33 months & $\begin{array}{l}\text {-Age-related microvascular } \\
\text { pathology (thinning, } \\
\text { irregularity, string vessels) } \\
\text {-Reduced microvascular length } \\
\text {-Noncongophilic pathology in } \\
\text { cortical penetrating vessels } \\
\text {-Abnormal immunostaining of } \\
\text { basement membrane-associated antigens } \\
\text {-Thickening of vascular basal } \\
\text { laminae } \\
\text {-Hippocampal atrophy } \\
\text {-Altered dendritic structure }\end{array}$ \\
\hline $\begin{array}{l}\text { Non-Tg littermates of } \\
\text { PAC mice }\end{array}$ & None & 4 to 37 months & None \\
\hline NSE-PS1 wild-type Tg & $\begin{array}{l}\text { Human wild-type PS1 cDNA under } \\
\text { control of NSE promoter }\end{array}$ & 4 to 22 months & None \\
\hline NSE-P117L Tg & $\begin{array}{l}\text { Human PS1 CDNA containing the P117L } \\
\text { FAD mutation under control of the NSE } \\
\text { promoter }\end{array}$ & 4 to 24 months & Similar to PS1 PAC M146V \\
\hline $\begin{array}{l}\text { Non-Tg littermates of } \\
\text { NSE mice }\end{array}$ & None & 4 to 24 months & None \\
\hline
\end{tabular}

Tg, transgenic. 
from the pCR2.1 vector by Xhol-Hindlll digestion and subcloned into the Xhol-Hindlll sites of pDF26 (resulting in the plasmid pDFPS1M146V), which was transformed into $E$. coli XL blue cells (Stratagene) and chloramphenicol-resistant clones were selected at $30^{\circ} \mathrm{C}$. Plasmid DNA from a pDFPS1M146V-positive clone was transformed into E. coli DH10 cells harboring the Kan ${ }^{\mathrm{R}}$ PAC 54D12. Double transformants (pDFPS1M146V/PAC54D12) were selected on plates containing kanamycin and chloramphenicol at $30^{\circ} \mathrm{C}$ and then transferred to fresh kanamycin/chloramphenicol plates and grown overnight at $43^{\circ} \mathrm{C}$ (the nonpermissive temperature). To select for recombinant clones harboring PDFPS1M146V integrated into the homologous region of PAC54D12 via recA activity, correct type I and II integrations were identified by Southern blot analyses (using the above 1.6-kb fragment harboring PS1 exon 6 sequences as probe). Positive clones were grown overnight at $43^{\circ} \mathrm{C}$ on kanamycin-containing plates to allow excision of the integrated vector sequences. In these recombination events, either the original copy or the targeted sequence containing the modified M146V mutation is left behind. Excised vector PAC clones were further selected at $43^{\circ} \mathrm{C}$ on kanamycin/streptomycin plates, permitting the growth of only bacterial clones that excised the pDF $\mathrm{rpsL}^{+}$vector sequences. Identification of PAC clones harboring the M146V mutation (PACPS1M146V) was performed as follows: a 0.25-kb fragment harboring the PS1 exon 6 sequences of interest (nucleotides 136,351-136,600 of the reference PAC 54D12) was amplified from individual PAC clones with the primer pair 5'-TGACAAGAATACCCAACCAT-3' and 5'-TCCATTAACACTGACCTAGG-3', digested with $\mathrm{BspHI}$ and analyzed by agarose gel electrophoresis. The M146V mutation was detected by the loss of one of the two $\mathrm{BspHI}$ restriction sites in exon 6. About 50\% of the clones tested harbored the M146V mutation. DNA from two individual mutant PS1PAC M146V clones was isolated and analyzed as previously described. ${ }^{16}$ The purified DNA was adjusted to a concentration of $1 \mu \mathrm{g} / \mathrm{ml}$ in 10 $\mathrm{mmol} / \mathrm{L}$ Tris- $\mathrm{HCl}, \mathrm{pH}$ 7.5, $0.5 \mathrm{mmol} / \mathrm{L}$ EDTA, $30 \mathrm{nmol} / \mathrm{L}$ spermine, $70 \mathrm{nmol} / \mathrm{L}$ spermidine, $0.1 \mathrm{M} \mathrm{NaCl}$ and transgenic mice were generated by pronuclear injection into C57BL/6 $\times$ C3H F oocytes. Genotyping of tail DNA by $\mathrm{PCR} / \mathrm{BspHI}$ restriction analyses identified 5 founders out of 18 births. Routine genotyping was performed by PCR of genomic DNA from tail biopsies with the primer pair described above followed if necessary by $\mathrm{BspHI}$ digestion to confirm the presence of the wild-type or M146V-mutant allele. Lines were maintained by breeding to C57BL/6 mice.

The $P S 1^{-1-}$ mice used were those generated by Shen et al. ${ }^{18}$ These animals were provided on a mixed genetic background and have been maintained by breeding to C57BL/6 wild-type mice. Genotypes were determined by PCR as described in Shen et al. ${ }^{18}$ Animals were housed on 12 hour light/dark cycles and received food and water ad libitum. Because of the mixed genetic background of all of the lines, nontransgenic littermates were used as controls. All protocols were approved by the Institutional Animal Care and Use Committees of the James J. Peters Department of Veterans Affairs Medical Center and the Mount Sinai School of Medicine and were conducted in conformance with Public Health Service policy on the humane care and use of laboratory animals and the National Institutes of Health Guide for the Care and Use of Laboratory Animals.

\section{Tissue Processing}

Adult mice were anesthetized with $150 \mathrm{mg} / \mathrm{kg}$ ketamine and $30 \mathrm{mg} / \mathrm{kg}$ xylazine and sacrificed by transcardial perfusion with cold $4 \%$ paraformaldehyde in PBS. After perfusion, brains were removed and postfixed in $4 \%$ paraformaldehyde for 48 hours, transferred to PBS, and stored at $4^{\circ} \mathrm{C}$ until sectioning. Fifty-micrometer-thick coronal sections were cut using a Leica VT1000 S Vibratome (Leica, Wetzlar, Germany).

\section{Histology and Immunohistochemistry}

H\&E staining was performed using standard methods. Thioflavin S staining was performed as described in Schmidt et al. ${ }^{19}$ Immunohistochemical staining was performed on free-floating sections. For immunofluorescence staining, the primary antibodies used were a rabbit polyclonal anti-collagen IV antiserum (1/500; Chemicon International, Temecula, CA), a rabbit polyclonal antilaminin antiserum (1/100; Sigma-Aldrich, St. Louis, MO), a rabbit polyclonal anti-fibronectin antiserum (1:400; Sigma-Aldrich), a rat monoclonal anti-perlecan antiserum (1:500; Neomarkers, Fremont, CA), a rabbit polyclonal anti-A $\beta$ antiserum (1/200 dilution; Chemicon International), and a mouse monoclonal anti- $\beta$-III tubulin (TuJ1, 1/500; Covance Research Products, Denver, PA). Sections were blocked with Tris-buffered saline (TBS; 50 $\mathrm{mmol} / \mathrm{L}$ Tris- $\mathrm{HCl}, 0.15 \mathrm{M} \mathrm{NaCl}(\mathrm{pH} 7.6)$, and $0.15 \mathrm{M}$ $\mathrm{NaCl} / 0.1 \%$ Triton $\mathrm{X}-100 / 5 \%$ goat serum (TBS-TGS) for 1.5 hours, and the primary antibody was applied overnight in TBS-TGS at room temperature. Following washing in PBS for 1 hour, immunofluorescence staining was detected by incubation with species-specific AlexaFluor secondary antibody conjugates (1/400; Molecular Probes, Burlingame CA) for 2 hours in TBS-TGS. Nuclei were counterstained with $1 \mu \mathrm{g} / \mathrm{ml}$ 4',6-diamidino-2-phenylindole. After washing in PBS, sections were mounted on slides using Gel/Mount (Biomeda, Foster City, CA). Sections incubated with secondary antibody only were used as controls.

Immunoperoxidase staining for collagen IV was performed on pepsin-digested tissue using methods similar to those described previously. ${ }^{20}$ The sections were pretreated with $10 \%$ methanol/1\% hydrogen peroxide in PBS for 10 minutes, washed in PBS and treated with $1 \mathrm{mg} / \mathrm{ml}$ pepsin (Dako, Carpinteria, CA) in 3\% acetic acid for 50 minutes at $50^{\circ} \mathrm{C}$. After washing in PBS, the primary antibody was applied as described above followed by a goat anti-rabbit horseradish peroxidase-conjugated secondary antibody (1/300, Santa Cruz Biotechnology, Santa Cruz, CA) for two hours. Staining was visualized using $3,3^{\prime}$-diaminobenzidine (DAB) in $50 \mathrm{mmol} / \mathrm{L}$ Tris-imidazole buffer, $\mathrm{pH}$ 7.6. Sections were mounted on slides, dried overnight and counterstained with $0.5 \%$ cresyl violet for 5 minutes followed by dehydration with a graded series of 
ethanol solutions (70, 85, 90, 100\% for 1 minute each). Slides were then treated with Americlear (Fisher, Tustin, CA) for 1 minute, followed by xylene for 1 minute and coverslipped with Cytoseal 60 (Richard-Allan Scientific, Kalamazoo, MI).

Stained sections were photographed on a Zeiss Axioimager microscope using the AxioVision Release 4.3 program (Zeiss, Thornwood, NY), a Nikon Eclipse E400 connected to a DXC-390 CCD camera (Nikon, Melville, NY) or a Zeiss LSM 510 confocal microscope. Unstained sections of fixed brain were photographed on a Nikon SMZ1500 stereomicroscope equipped with an oblique coherent contrast illumination system and connected to a SPOT RT digital camera (Sterling Heights, MI). Digital images were color balanced using Adobe Photoshop 7.0 (Adobe Systems, San Jose, CA).

\section{In Situ Hybridization}

For in situ hybridization, brains were embedded in OCT compound (Tissue Tek, Elkhart, IN). Fifteen-micrometerthick cryostat sections were air dried for 1 to 2 hours and fixed in 4\% paraformaldehyde in PBS-diethylpyrocarbonate. Sections were treated with $1 \mathrm{mg} / \mathrm{ml}$ proteinase $\mathrm{K}$ for 5 minutes at room temperature and fixed in paraformaldehyde for an additional 20 minutes. After several washes with PBS-diethylpyrocarbonate, sections were acetylated with acetic anhydride in the presence of triethanolamine. The sections were then prehybridized for 2 hours in 50\% formamide, $5 \times$ saline sodium citrate, $5 \times$ Denhardt's solution, $250 \mu \mathrm{g} / \mathrm{ml}$ yeast RNA, and $500 \mu \mathrm{g} / \mathrm{ml}$ herring sperm DNA and hybridized at $70^{\circ} \mathrm{C}$ for 16 hours with 400 $\mathrm{ng} / \mathrm{ml}$ of a heat-denatured $\left(80^{\circ} \mathrm{C}\right)$ digoxigenin-labeled anti-sense RNA probe. To prepare a human PS1-specific probe we amplified a fragment spanning nucleotides 1891-2315 of human PS1 3' untranslated region (accession number NM_000021), an area of very low homology between human and mouse PS1 with the primers 5'ACTACCAGATTTGAGGGACGAG-3' and 5'-GGCAATCACAGACGGTAATGAG-3'. The resulting 424-bp human PS1 DNA product was cloned into the pDrive vector (Qiagen, Valencia, CA). An antisense human-specific CRNA probe was prepared with Xhol-linearized plasmid in the presence of digoxigenin-labeled uridine triphosphate in addition to the other nucleotides and T7 RNA polymerase. Slides were washed for 1 hour in $0.2 \times$ saline sodium citrate at $70^{\circ} \mathrm{C}$ and subsequently with $50 \mathrm{mmol} / \mathrm{L}$ Tris- $\mathrm{HCl}(\mathrm{pH} \mathrm{7.6)}$ and $0.15 \mathrm{M} \mathrm{NaCl}$ (TBS) at room temperature. Slides were blocked with $10 \%$ heat-inactivated goat serum in TBS at room temperature and incubated overnight with a 1/250 dilution of anti-digoxigenin antibodies at $4^{\circ} \mathrm{C}$ (Roche, Basel, Switzerland). After several washes with TBS, slides were equilibrated in alkaline phosphatase buffer (0.1 M Tris- $\mathrm{HCl}(\mathrm{pH} 9.5), 0.1 \mathrm{M} \mathrm{NaCl}$, $50 \mathrm{mmol} / \mathrm{L} \mathrm{MgCl}_{2}, 0.01 \%$ Tween-20, and $0.25 \mathrm{mg} / \mathrm{ml}$ levamisole) for 30 minutes, followed by staining with 0.4 $\mathrm{mg} / \mathrm{ml}$ nitroblue tetrazolium chloride, and $0.19 \mathrm{mg} / \mathrm{ml}$ 5-bromo-4-chloro-3-indolyl-phosphate in the same solution for 72 hours at $4^{\circ} \mathrm{C}$.

\section{Western Blotting}

For determination of PS1 levels, brains were homogenized in 10 volumes of radioimmunoprecipitation assay buffer (50 mmol/L Tris- $\mathrm{HCl}(\mathrm{pH} 7.6), 0.15 \mathrm{M} \mathrm{NaCl}, 1$ $\mathrm{mmol} / \mathrm{L}$ EDTA, $1 \%$ Triton $\mathrm{X}-100,1 \%$ sodium deoxycholate, and $0.1 \%$ SDS) containing HALT protease and phosphatase inhibitor mixtures (Pierce, Rockford, IL). The samples were centrifuged at 15,000 rpm for $20 \mathrm{~min}$ utes and the supernatant collected. Protein concentrations were determined using the BCA reagent assay (Pierce). Protein samples were mixed with Laemmli buffer and loaded without boiling onto SDS-PAGE gels. Gels were blotted onto polyvinylidene difluoride membranes (Millipore, Billerica, MA). The blots were blocked with 50 mmol/L Tris- $\mathrm{HCl}(\mathrm{pH} 7.6), 0.15 \mathrm{M} \mathrm{NaCl}, 0.1 \%$ Tween-20 (TBST), and 5\% nonfat dry milk and probed with the mouse monoclonal antibody NT.1 (1/2000), which recognizes the human PS1 N-terminal fragment (NTF) or with the mouse monoclonal antibody 33B10 (1/3000), which recognizes both human and mouse PS1 C-terminal fragment (CTF) followed by secondary detection with horseradish peroxidase conjugated goat anti-mouse IgG. The bands were visualized with the ECL+ reagent (GE Healthcare Bio-Sciences, Piscataway, NJ) and exposure to CL-Xposure film (Pierce).

For blotting of basement membrane associated proteins, one cerebral hemisphere from each animal was homogenized in $50 \mathrm{mmol} / \mathrm{L} \mathrm{Na}$ Phosphate $\mathrm{pH}$ 7.6, 150 $\mathrm{mmol} / \mathrm{L} \mathrm{NaCl}, 1 \mathrm{mmol} / \mathrm{L}$ EDTA, $1 \%$ Triton, $0.25 \%$ sodium deoxycholate, $0.5 \%$ SDS buffer supplemented with Halt protease and phosphatase inhibitor mixtures I and II (Sigma-Aldrich). The homogenates were centrifuged at 14,000 rpm for 20 minutes, and the supernantants were removed. Protein concentration was determined as above, and for blotting, $50 \mu \mathrm{g}$ of protein per sample was run on $7.5 \%$ SDS-PAGE gels and blotted onto polyvinylidene difluoride membranes. For collagen IV analysis, the samples were mixed with Laemmli buffer without mercaptoethanol and not boiled before loading on the gel. The membranes were blocked for 1 hour as described above and incubated overnight at $4^{\circ} \mathrm{C}$ with primary antibodies diluted in blocking solution followed by secondary detection with horseradish peroxidase-conjugated anti-rabbit IgG (1/5000 in blocking solution with only $1 \%$ nonfat dry milk; GE Healthcare Bio-Sciences). The bands were visualized with ECL+ reagent (GE Healthcare Bio-Sciences) and exposure to HyBlot CL film (Denville Scientific, Metuchen, NJ) and/or imaging with a Kodak Image Station 4000R. As needed blots were stripped with Reblot plus strong (Millipore) and reprobed. The primary antibodies used were a rabbit polyclonal anti-fibronectin (1/3000; Sigma-Aldrich), rabbit polyclonal anti-laminin (1/ 500; Sigma-Aldrich), and rabbit polyclonal anti-collagen IV (1/3000; Abcam, Cambridge, UK). A rabbit polyclonal anti- $\beta$-tubulin (1/3000; Abcam) was used as a loading control. Quantitation was performed with Image Quant TL software (GE Healthcare Bio-Sciences) with normalization to the level of $\beta$-tubulin. 


\section{Stereologic Analysis}

Brains were cut in serial $50-\mu m$-thick coronal sections using a Vibratome (Leica). Every sixth section was chosen, beginning with a random section between 1 and 6 and immunostained for collagen IV as described above. To reduce bias, all analyses were performed blind to genotype. For stereologic analyses, collagen IV-immunostained sections were first viewed at low magnification $(\times 2.5)$ to outline the hippocampal borders using a Zeiss Axioplan 2 microscope and Stereolnvestigator software (MBF Bioscience, Williston, VT). Vascular area and length was then examined using the software's Space Balls probe $^{21-24}$ using a $\times 40$ oil Zeiss PlanApochromat objective, 1.0 n.a. The dimensions of the random sampling grid used were set at $x=310 \mu \mathrm{m}, y=300 \mu \mathrm{m}$, and a hemisphere with a radius of $15 \mu \mathrm{m}$ was used. A $0.5-\mu \mathrm{m}$ guard zone was set at the top and bottom of the tissue to avoid counting in the compromised cut surface while the remainder of the tissue thickness represented the disector height; the mean section thickness was $18.3 \mu \mathrm{m}$. Sampling grids were systematically and randomly placed by the stereology software throughout the region of interest. Vascular length density was calculated from the total number of intersections between the vasculature and the hemispheres (mean number of counted intersections = 335), using the following formula derived from the description of the Space Balls method and using the area of the delineated region and section thickness after tissue processing:

$$
\mathrm{VLD}=\frac{2 \times \text { is } \times\left(\mathrm{D}_{X} \times \mathrm{D}_{Y} \times t\right)}{2 \times \pi \times r^{2}} \times \frac{1}{V}
$$

where VLD represents the capillary length density, $\Sigma$ is the total number of intersections between the hemispheres and the microvessels, $D_{X}$ and $D_{Y}$ the distance between the midpoints of the centers of the hemispheres in the $x$ and $y$-axes, $t$ the actual average section thickness after histological processing, $r$ the radius of the hemispheres and $V$ the investigated tissue volume. When using stereologic techniques on processed tissue, tissue volume change is always of concern. In this study, tissue sections were mounted soon after cutting and before staining, which minimizes shrinkage in the $x-y$ directions. ${ }^{22}$ Shrinkage in the $z$-direction can be substantial; the stereology software corrected for this by measuring the true section thickness at regular intervals and using this factor in calculating total vascular length and hippocampal volume.

\section{Ultrastructural Analyses}

The method used for electron microscopy has been described previously. ${ }^{25}$ Briefly, the embedding technique followed the procedure as described ${ }^{26}$ to study the ultrastructure of blood vessels. Mice from each genotype were anesthetized and perfused as described above with $4 \%$ paraformaldehyde containing $0.125 \%$ glutaraldehyde. Tissue was removed and postfixed in the same perfusate overnight. Brains were then removed and 250- $\mu \mathrm{m}$-thick coronal sections were cut using a Vibratome and relevant cortical blocks were dissected out. Freeze substitution and low-temperature embedding of the specimens was performed as described elsewhere. ${ }^{26-28}$ The slices were cryoprotected by immersion in 4\% Dglucose, followed with increasing concentrations of glycerol (from 10 to $30 \%$ in phosphate buffer; v/v). Sections were plunged rapidly into liquid propane cooled by liquid nitrogen $\left(-190^{\circ} \mathrm{C}\right)$ in a Universal Cryofixation System KF80 (Reichert-Jung, Vienna, Austria). The samples were immersed in $0.5 \%$ uranyl acetate dissolved in anhydrous methanol $\left(-90^{\circ} \mathrm{C}, 24\right.$ hours) in a cryosubstitution AFS unit (Leica, Vienna, Austria). The temperature was raised from $-90^{\circ} \mathrm{C}$ to $-45^{\circ} \mathrm{C}$ in steps of $4^{\circ} \mathrm{C} / \mathrm{h}$. After washing with anhydrous methanol, the samples were infiltrated with Lowicryl HM20 resin (Electron Microscopy Sciences, Fort Washington, PA) at $-45^{\circ} \mathrm{C}$. Polymerization with UV light (360 nm) was performed for 48 hours at $-45^{\circ} \mathrm{C}$, followed by 24 hours at $0^{\circ} \mathrm{C}$. Ultrathin sections $(70 \mathrm{~nm})$ were cut with a diamond knife on a Reichert-Jung ultramicrotome and mounted on nickel grids using a Coat-Quick adhesive pen (Electron Microscopy Sciences). Ultrastructural analyses were performed on a JEOL 1200 EX electron microscope (Tokyo, Japan) and imaged with an advantage CCD camera (Advanced Microscopy Techniques, Danvers, MA). Electron microscopy images were produced using Adobe Photoshop 7.0 and adjusted for brightness and contrast.

\section{Statistical Procedures}

Results are presented as mean \pm the SEM. For all comparisons the equality of variance was first assessed by Levene's test. As none of the variances were found to differ significantly ( $P>0.05$, Levene statistic) comparisons were made using a one-way analysis of variance followed by a Tukey honestly significant difference (HSD) test for multiple comparisons of all pairs of groups or using unpaired Student's t-tests when two groups were compared. Statistical analyses were performed using the program GraphPad Prism 4.0 (GraphPad Software, San Diego, CA) or SPSS 16.0 (SPSS, Chicago, IL).

\section{Results}

\section{Generation of PAC Transgenic Mice Expressing Human Wild-Type or M146V FAD-Mutant PS1}

Transgenic mice expressing human wild-type PS1 were generated using a P1 artificial chromosome (PAC) clone (54D12) containing the human PS1 transcription unit. To create transgenic mice expressing an FAD mutant, the PAC54D12 clone was retrofitted with the M146V PS1 FAD mutation using Rec-A mediated homologous recombination. We selected for study two lines of mice (one wildtype and one FAD mutant) that expressed similar levels of human PS1 in the brain as judged by Western blotting and that had similar patterns of transgene expression based on in situ hybridization. In Figure 1, Western blots 


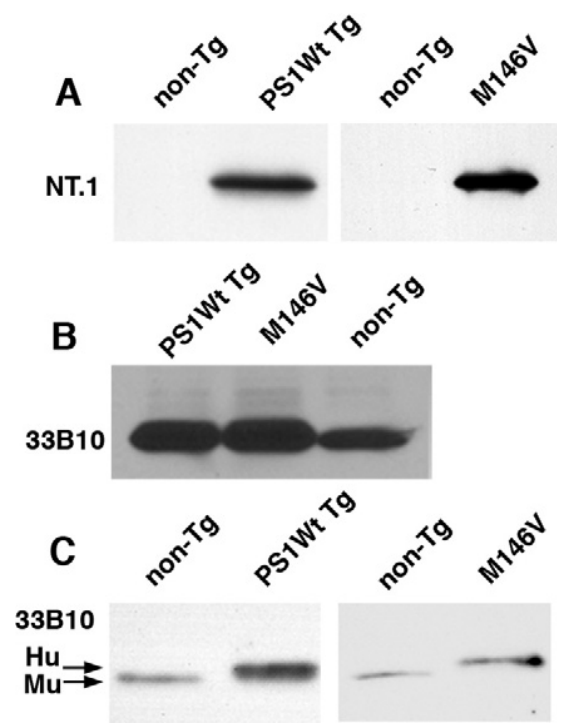

Figure 1. Transgene expression in PS1 PAC wild-type and PS1 PAC M146V transgenic mice. Western blotting was performed on extracts $(50 \mu \mathrm{g}$ of protein) from 2-month-old nontransgenic (non-Tg) littermate controls, human PS1 PAC wild-type transgenic (PS1 Wt Tg), or PS1 PAC M146V transgenic mice $(\mathrm{M} 146 \mathrm{~V})$. A: Blots were probed with NT.1, a human-specific antibody that recognizes the $\sim 30 \mathrm{kDa}$ human but not the mouse NTF. Note the lack of immunoreaction in the nontransgenic brain. B: The blot was probed with antibody 33B10, which recognizes both the mouse and human PS1 CTFs of $\sim 20 \mathrm{kDa}$. Note the comparable expression levels in the PS1 PAC wild-type and M146V-mutant lines and the elevation of total PS1 CTF in the transgenic lines compared with the nontransgenic. C: Blotting with 33B10 was repeated with less protein loaded $(25 \mu \mathrm{g})$. Note that the mouse (Mu) CTF is distinguishable from the human (Hu) CTF by its slightly faster migration and that in the transgenic lines the human protein has largely replaced the mouse.

of adult brain extracts are shown blotted with the human specific antibody NT.1, which recognizes the PS1 NTF or with the antibody 33B10, which recognizes the PS1 CTF. NT.1 recognized a unique band present in both transgenic lines that was not seen in non-transgenic brain (Figure 1A). Western blotting with 33B10 (Figure 1B), which was generated against a region of the PS1 protein that is identical in mouse and human, ${ }^{14}$ showed comparable levels of PS1 expression in the wild-type and FADmutant lines at levels about two- to threefold higher in transgenic compared with nontransgenic brain. Also of note is that the human CTF, which can be discriminated from the mouse CTF by its slower mobility, largely replaced the mouse PS1 (Figure 1C).

We analyzed transgene expression pattern in adult PS1 PAC transgenic mice by in situ hybridization using a human specific cRNA probe and a digoxigenin detection system. In both PS1 wild-type and FAD-mutant transgenic lines, the human transgene was expressed in all brain regions and exhibited a neuronal expression pattern mimicking that of the endogenous PS1 in adult mouse brain. ${ }^{29}$ An example of labeling in the hippocampus is shown in Figure 2.

To test whether the PS1 PAC transgenes could rescue the embryonic lethality of PS1 null-mutant mice $\left(P S 1^{-1-}\right)$ we bred the transgenes from the PS1 PAC wild-type and PS1 PAC M146V lines onto the mouse $P S 1^{-1-}$ background. Both wild-type and FAD-mutant transgenes rescued the embryonic lethality of the PS1
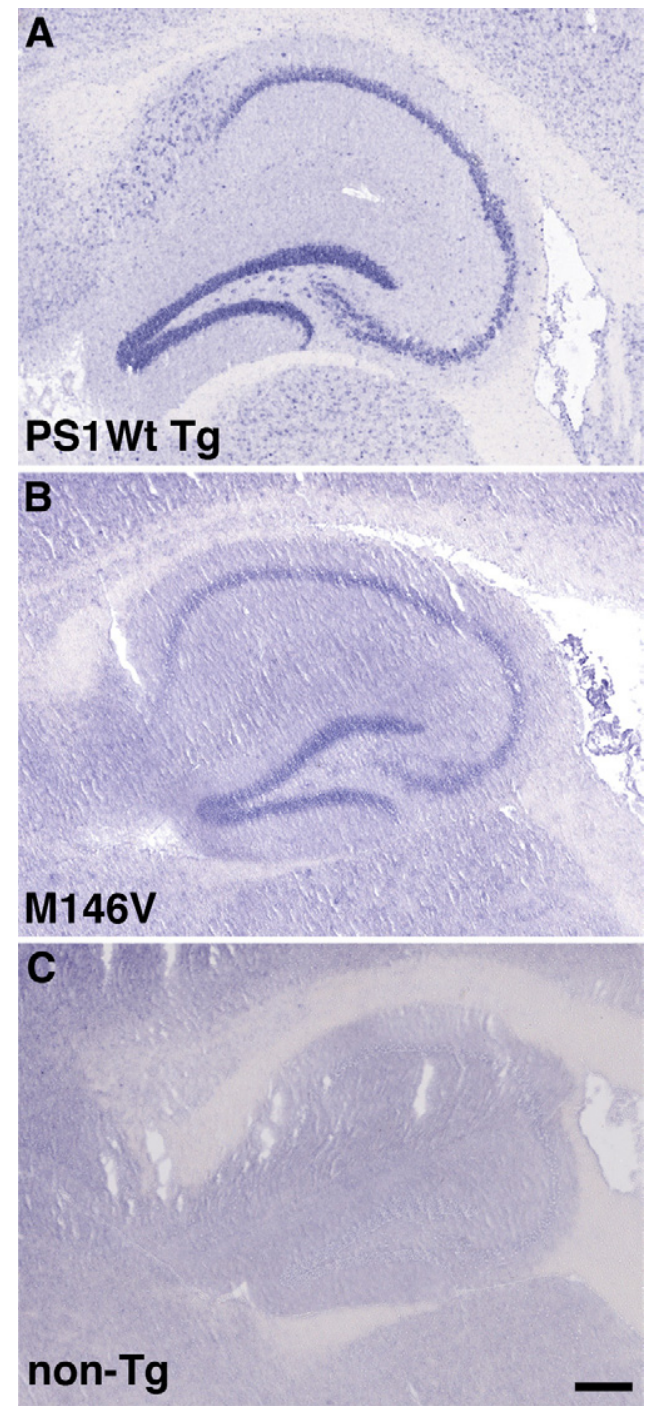

Figure 2. Transgene expression in PS1 PAC transgenic mice. In situ hybridization was performed on 2-month-old adult animals using a human-specific PS1 antisense cRNA probe derived from the 3 ' untranslated region of the gene. Shown are sagittal sections of hippocampus from a PS1 PAC wild-type transgenic (A), a PS1 PAC M146V transgenic (B), and a non-transgenic littermate control $(\mathbf{C})$. Note the lack of hybridization signal in the nontransgenic control brain (C) and the prominent labeling of the granule cell and pyramidal cell layers in the transgenic animals (A and B). Scale bar: $100 \mu \mathrm{m}$.

null mutant. Rescued adult animals appeared normal in size, were fertile, and grossly indistinguishable from their non-transgenic littermates. These results confirm the functionality of both the wild-type and FAD-mutant PAC transgenes in the mouse and are also consistent with other reports that PS1 FAD mutants can rescue the embryonic lethality of the PS1-null mouse. ${ }^{30,31}$

\section{Age-Related Microvascular Pathology in PS1 FAD-Mutant Transgenic Mice}

Vascular pathology in human AD includes CAA, which is observed mostly in small arteries and arterioles as well as a distinctive alteration of the cerebral microvasculature with vascular attrition and the appearance of a variety of 


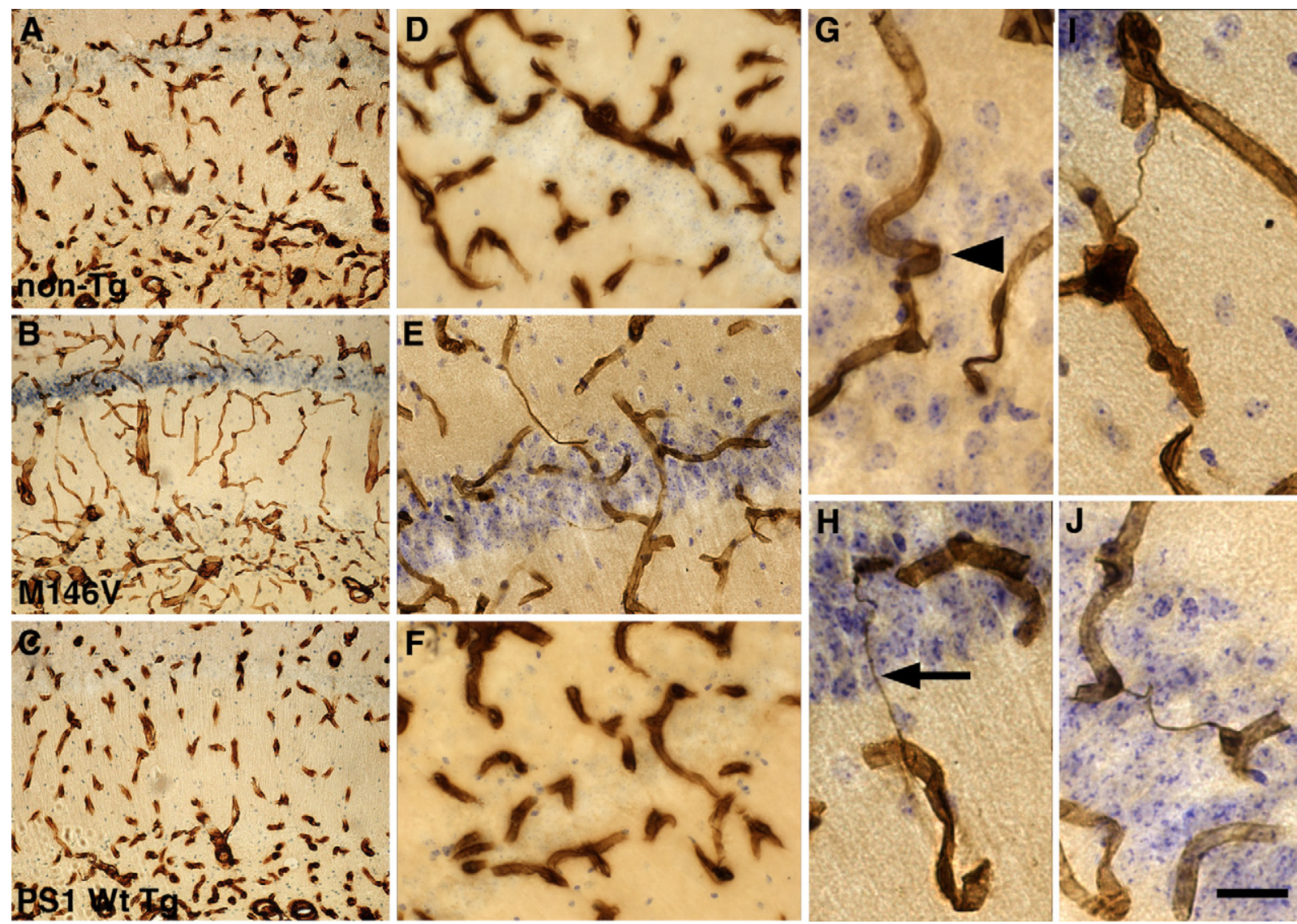

Figure 3. Age-related vascular alterations in PS1 PAC M146V transgenic mice. Anti-collagen IV immunoperoxidase-stained sections of the hippocampus from 28-month-old nontransgenic control (A and D), 27-month-old PS1 PAC M146V transgenic (B, E, and G-J), and 28-month-old PS1 PAC wild-type transgenic (C and F) mice. Note the thinning of the microvessels in the FAD mutant (B and $\mathbf{E})$. Higher magnification images of microvessels from the FAD mutant are shown in $\mathbf{G}-\mathbf{J}$. A twisted and kinked vessel is indicated by an $\operatorname{arrowhead}(\mathbf{G})$, and a string-like vessel is indicated by an $\mathbf{a r r o w}(\mathbf{H})$. Scale bar: $100 \mu \mathrm{m}, \mathbf{A}-\mathbf{C} ; 50 \mu \mathrm{m}, \mathbf{D}$ and $\mathbf{E} ; 20 \mu \mathrm{m}, \mathbf{G}-\mathbf{J}$.

abnormal vessels. ${ }^{5}$ To determine whether PS1 FAD-mutant mice exhibit vascular pathology, we examined PS1 PAC M146V transgenic mice as well as mice that express the PS1 P117L FAD mutation under the control of the NSE promoter. The NSE lines were developed previously and express a human cDNA containing the P117L FAD mutation. ${ }^{14}$ As controls, we generated lines that express a wild-type human PS1 cDNA driven by the same promoter. Control lines were selected that expressed similar levels and patterns of PS1 expression as the FAD mutants based on Western blotting and in situ hybridization. ${ }^{14}$ Like other PS1 FAD-mutant mice, ${ }^{32}$ NSE-P117L FAD-mutant mice have elevated levels of $A \beta 42$ and an increased ratio of $A \beta 42 / 40^{13}$ compared with nontransgenic and NSE-PS1 wild-type transgenic mice, indicating the functionality of the P117L-mutant transgene.

Initially we examined vascular morphology using collagen IV immunostaining to visualize blood vessels. In young PS1 FAD-mutant M146V or P117L mice (6 months of age or less), we noted no abnormalities. However, we consistently observed vascular pathology with aging in both M146V and P117L FAD-mutant mice. Examples of the pathology in the hippocampus of PS1 PAC M146V transgenic mice are shown in Figure 3. Compared with controls, microvessels in the FAD-mutant mice were often thinner and irregular. In addition many string-like vessels (eg, Figure $3 \mathrm{H}$ ) were observed while other vessels dis- played a kinked or twisted morphology (eg, Figure 3G). The thinning and irregularity as well as the strings and twisted morphologies are highly reminiscent of the vascular pathology seen in AD. ${ }^{5}$ These changes were found
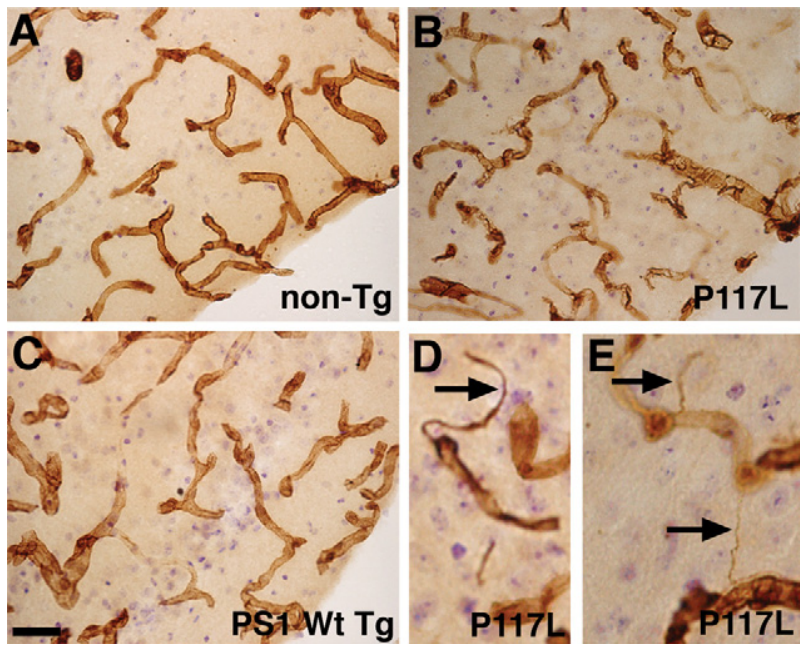

Figure 4. Microvascular pathology in NSE-P117L FAD mutant mice. Anticollagen IV immunoperoxidase-stained microvessels in the entorhinal cortex of 2-year nontransgenic (A), NSE-P117L transgenic (B, D, and E), and NSEPS1 wild-type transgenic (C) mice. Note the irregularity of the vascular surfaces in the FAD mutant (B). Arrows in $\mathbf{D}$ and $\mathbf{E}$ point to string-like vessels found in the FAD mutant. Scale bar: $50 \mu \mathrm{m}, \mathbf{A}-\mathbf{C} ; 25 \mu \mathrm{m}, \mathbf{D}$ and $\mathbf{E}$. 
widely in both cortical and subcortical regions. We consistently observed some degree of this pathology in mice 1 year of age or older with the pathology becoming more apparent in older mice. No morphological differences were seen with aging between the nontransgenic controls and the human PS1 PAC wild-type transgenic mice.

We also observed a similar age-related vascular pathology in NSE-P117L transgenic mice (Figure 4). This pathology has been consistently seen in NSE-P117L transgenic mice $>1$ year of age and is not found in age-matched nontransgenic littermates or in NSE-PS1 wild-type transgenic mice. Although some mild irregularities can be seen at times in normal vessels (eg, Figure $4 C$ ), these changes never approached the degree of irregularity seen in PS1 FAD-mutant vessels making both lines of PS1 FAD-mutant mice easily distinguishable from controls on a morphological basis.

\section{Decreased Microvasculature and Brain Atrophy in Aging PS1 PAC M146V Transgenic Mice}

Vascular loss is a hallmark of the microvascular pathology in $A D .^{5}$ To determine whether the vascular pathology observed in PS1 PAC M146V transgenic mice was accompanied by a reduced microvasculature we performed stereologic assessments of collagen IV-immunostained microvessels in the hippocampus in groups of 15 month or older PS1 PAC M146V and PS1 PAC wild-type transgenic mice as well as nontransgenic littermate controls. As shown in Figure 5, compared with the control groups, total vascular length was lower by 40 to $45 \%$ in the FAD mutant: falling from $772 \pm 130 \mathrm{~cm}$ (SEM) and $720 \pm 43 \mathrm{~cm}$ in the nontransgenic and PS1 PAC wild-type transgenic mice, respectively, to $430 \pm 28 \mathrm{~cm}$ in the FAD mutant $\left(F_{2,12}=7.646, P=0.007, P<0.05\right.$, PS1 PAC M146V versus both PS1 PAC wild-type transgenic mice and nontransgenic littermate controls, Tukey HSD). Mean microvessel area was 25 to $30 \%$ less in the FAD mutant, but this difference did not reach statistical significance $\left(F_{2,12}=2.863, P=0.096\right)$. The microvascular density differed by $<20 \%$ between the groups $\left(F_{2,11}=0.890\right.$, $P=0.43$ ).

The reduced vascular length without any change in vascular density was suggestive of concomitant hippocampal atrophy, and indeed, there was frequently visible brain atrophy in M146V FAD-mutant mice, including gross atrophy of the hippocampus in the oldest mice (Figure 6). A quantitative analysis showed that hippocampal volume was reduced by $\sim 30 \%$ in the FAD-mutant group compared with a pooled control group of nontransgenic and PS1 PAC wild-type transgenic mice (Figure 6; $P=0.012$, unpaired $t$-test). Whereas the basis for the brain atrophy remains to be explored in depth, one aspect of the pathology appears to be attrition of dendritic structure in the FAD-mutant animals. This attrition was most apparent in neocortical large pyramidal neurons. In Figure $7, \beta$-III tubulin-immunostained sections of the neocortex are shown from a 7.5-month-old M146V FAD-mutant as well as control mice imaged by confocal microscopy. Marked alterations of the dendritic structure are

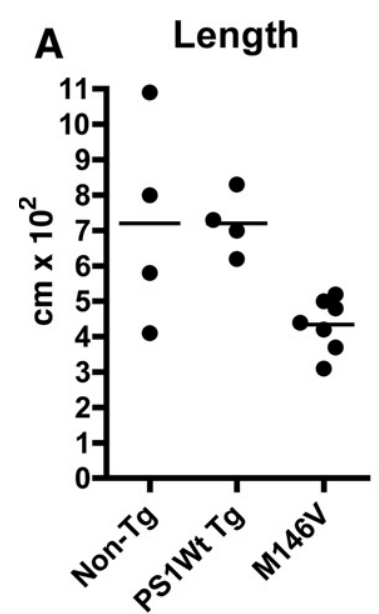

\section{B Length}
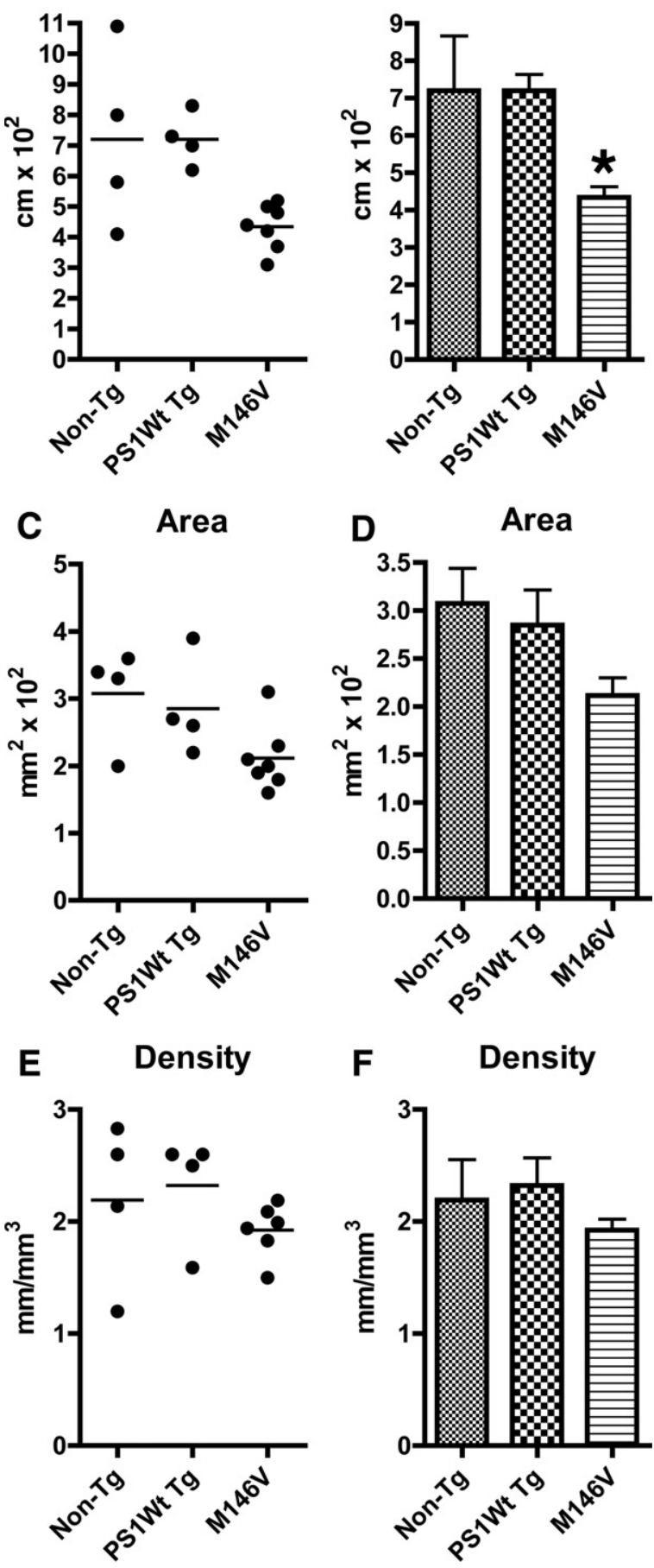

$\mathbf{F}$

Density

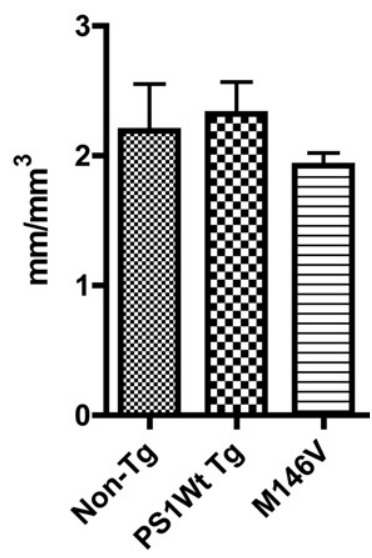

Figure 5. Decrease in microvessel length in the hippocampus of PS1 PAC M146V transgenic mice. Vascular parameters were assessed stereologically in the hippocampus of PS1 M146V PAC mice ( $n=7$, age range 15 to 33 months, average $24.4 \pm 2.6$ months) and were compared with control groups of nontransgenic (Non-Tg) littermates ( $n=4$, age range 28 to 37 months, average $32.5 \pm 1.8$ months) and PS1 PAC wild-type transgenic (PS1Wt Tg) mice ( $n=4$, age range 18 to 28 months, average $22.5 \pm 2.6$ ). A one-way analysis of variance revealed that the groups did not significantly differ by age $\left(F_{2,12}=3.462, P=0.06, P>0.07\right.$ all comparisons, Tukey HSD $)$. Data are presented as total vessel length $(\mathbf{A}$ and $\mathbf{B})$ and area $(\mathbf{C}$ and $\mathbf{D})$ per hippocampus $(\mathbf{C}$ and $\mathbf{D})$ as well as microvessel density $(\mathbf{E}$ and $\mathbf{F}) .{ }^{*} P=0.01$ versus non-Tg and $P=0.03$ versus PS1 Wt Tg (Tukey HSD). 

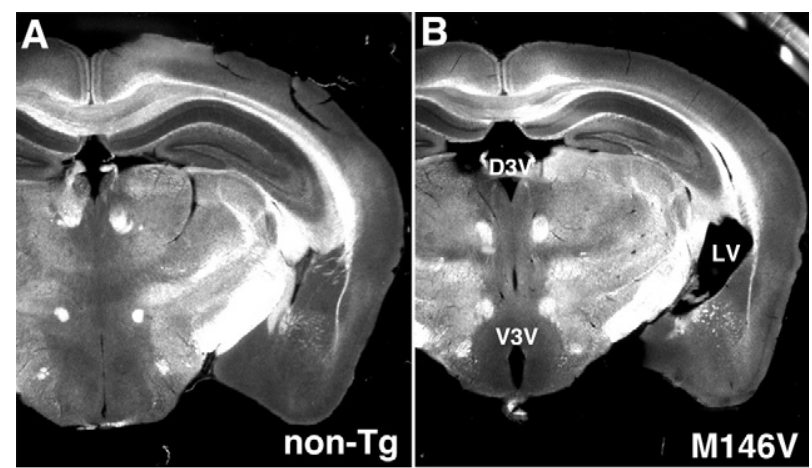

\section{Hippocampal volume}

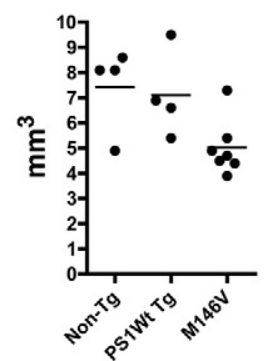

D

\section{Hippocampal volume}

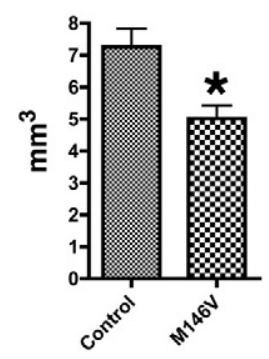

Figure 6. Age-related brain atrophy in PS1 PAC M146V transgenic mice Coronal sections of unstained fixed brain from 3-year-old nontransgenic (A) and M146V PAC transgenic littermate mice $(\mathbf{B})$ are shown. The lateral ventricle (LV), as well as the dorsal (D3V) and ventral (V3V), portions of the third ventricle are indicated. $\mathbf{C}$ and $\mathbf{D}$ : Hippocampal volumes of the same mice analyzed in Figure 5. Average hippocampal volume was 30\% lower in the M146V FAD-mutant mice compared with either control group with a oneway analysis of variance revealing significant between group differences $\left(F_{2,12}=3.921, P=0.049\right)$, although posttests did not reach statistical significance $(P>0.09$, Tukey HSD). However, if the two control groups (non-Tg and PS1 Wt Tg), which did not differ $(P=1.00)$, were treated as a pooled control, hippocampal volumes (D) in the M146V FAD-mutant mice were significantly lower ${ }^{*} P=0.012$, vs. control (unpaired $t$-test).

apparent in the FAD mutant. Although it is not possible to infer a direct causal relationship, the microvascular pathology seen in PS1 PAC M146V transgenic mice appears to be associated with substantial brain atrophy.

\section{Vascular Pathology in PS1 FAD-Mutant Mice Is Not Congophilic}

CAA involves the deposition of amyloid within blood vessels. It is the most recognized form of vascular pathology in human AD. To determine whether vascular pathology in PS1 FAD-mutant mice was associated with congophilic changes, we performed thioflavin S staining (Figure 8). We found no congophilic changes in either M146V or P117L FAD-mutant mice stained at various ages, even though congophilic changes were evident in a CRND8 transgenic mouse ${ }^{33}$ included as a positive control. We have also not found any evidence of $A \beta$ deposition by immunostaining in blood vessels of the PS1 FAD-mutant mice (data not shown).

Interestingly, despite the lack of congophilia, penetrating vessels at the cortical surface, which are most prone to CAA, were often abnormal morphologically in FADmutant mice. Examples of penetrating cortical vessels stained with $\mathrm{H} \& \mathrm{E}$ are shown in Figure 9. These vessels in the FAD-mutant lines, presumably arterioles based on their size, often showed a "cracked" appearance or an image of a "vessel within a vessel" associated with a widened perivascular space (Figure 9, C-E). Microhemorrhages, which are a feature commonly associated with CAA, were also sometimes observed (Figure 9F). Interestingly, the description of a "double barreling" or "vessel within a vessel," appearance has also been used to describe the appearance of thioflavin S-stained congophilic vessels found in human AD. ${ }^{34,35}$ However, the vessels described here did not exhibit congophilia or immunohistochemical evidence of $A \beta$ deposition.

\section{Altered Immunostaining of Microvessels in PS1 FAD-Mutant Animals with Basement Membrane-Associated Proteins}

Alterations of the vascular basement membranes have been suggested to be an early feature of the microvascular pathology in AD. ${ }^{36}$ The status of vascular basement
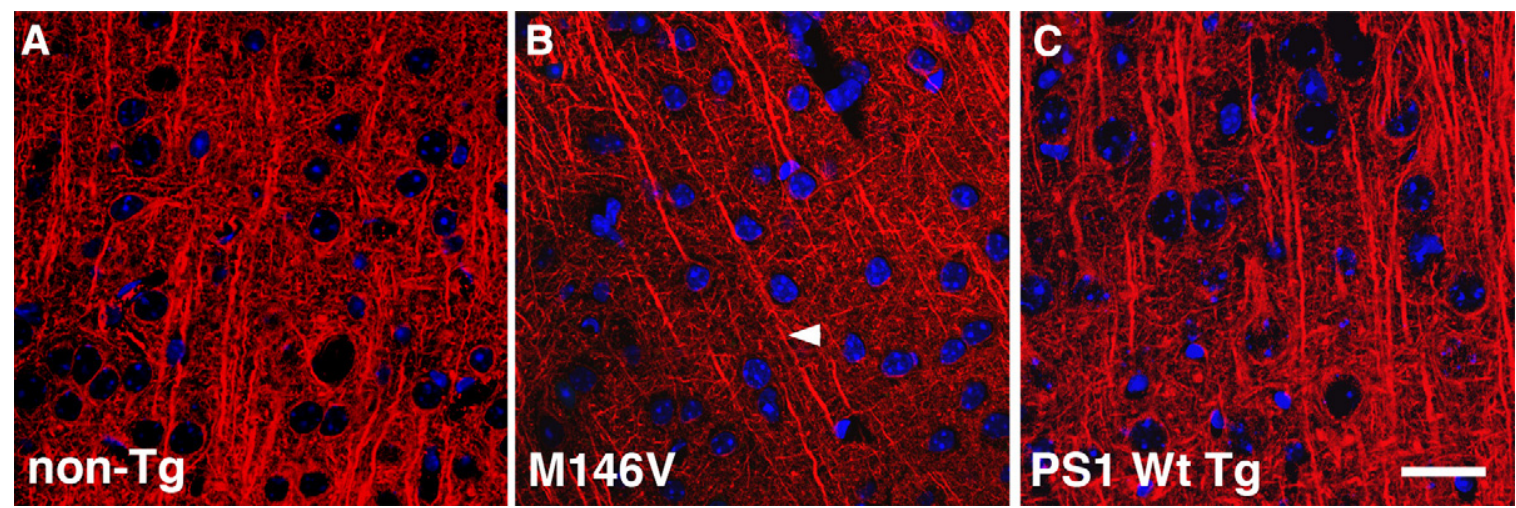

Figure 7. Altered dendritic structure in PS1 FAD-mutant mice. Shown are confocal laser scanning microscopy images of the neocortex from a 10 month old nontransgenic mouse (A), as well as 7.5-month-old PS1 M146V PAC (B), and PS1 PAC wild-type transgenic (C) mice. Sections were immunostained for $\beta$-III tubulin with the antibody Tuj (red) and counterstained with a 4',6-diamidino-2-phenylindole nuclear stain (blue). Note that the dendrites in the FAD mutant (one of which is indicated by an arrowhead) appear shorter and thinner. Scale bar: $20 \mu \mathrm{m}$. 

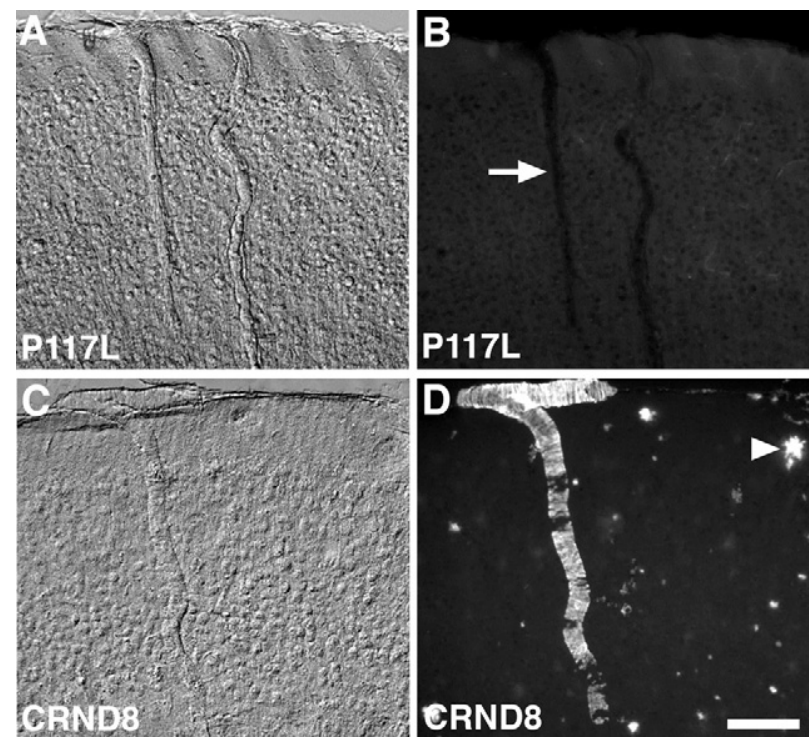

Figure 8. Vascular pathology is not congophilic in PS1 FAD mutant mice. Nomarski-imaged (A and $\mathbf{C}$ ) or thioflavin S-stained ( $\mathbf{B}$ and $\mathbf{D})$ sections from a 15-month-old NSE-P117L FAD-mutant transgenic mouse (A and $\mathbf{B})$ or a 1-year-old CRND8 transgenic mouse $(\mathbf{C}$ and $\mathbf{D})$ are shown. An arrow in $\mathbf{B}$ indicates a nonstained penetrating vessel at the cortical surface in the NSEP117L FAD-mutant mouse, likely an arteriole based on size. A thioflavin S-stained vessel from a CRND8 transgenic mouse is shown as a positive control (D). An amyloid plaque in the CRND8 mouse is indicated by an arrowhead in D. Scale bar: $100 \mu \mathrm{m}$.

membranes can be assessed by immunostaining for membrane-associated antigens. However, staining for many antigens including collagen IV occurs only inconsistently in perfusion-fixed materials from normal adult mice. ${ }^{20,37,38}$ We recently found that widespread staining of the brain vasculature in adult mice can be achieved with collagen IV as well as other antigens, if the immunostaining is preceded by a pepsin digestion step, ${ }^{20}$ a methodology that was used for the collagen IV staining described above.

Interestingly, however, vascular staining occurred in the brains of PS1 FAD-mutant mice with antigens such as collagen IV and perlecan even without pepsin digestion. In Figure 10, examples are shown of collagen IV vascular staining in PS1 PAC M146V-mutant and NSE-P117L transgenic lines. In contrast to non-transgenic or wildtype human transgenic lines, vascular staining was prominent in both FAD-mutant transgenic lines with collagen IV despite the lack of pepsin treatment. In Figure 11, examples of immunostaining of the hippocampus for the heparan sulfate proteogycan, perlecan, are shown in NSE-P117L FAD-mutant transgenic, NSE-PS1 wild-type transgenic and an age-matched nontransgenic mouse. Widespread vascular staining was seen with perlecan in the NSEP117L brain. In contrast, little to no perlecan immunoreactivity was detected in the nontransgenic or NSE-PS1 wild-type transgenic animal.

\section{Unaltered Levels of Basement Membrane-Associated Proteins in PS1} FAD-Mutant Transgenic Mice

The increased immunostaining of the microvasculature for basement membrane-associated proteins in PS1 FAD-mutant mice could be attributed to either increased expression of basement membrane-associated proteins or an altered presentation of antigens due to a reorganization of the vascular basement membrane. To determine whether total levels of vascular membrane-associated proteins were altered in the brain of FAD-mutant mice, we compared levels of fibronectin, laminin, and collagen IV by Western blotting in NSE-P117L FAD-mutant to nontransgenic control mice. As shown in Figure 12, we did not find any difference in total levels of fibronectin, laminin, or collagen IV in FAD-mutant brain. In combination with the altered immunostaining properties for these same antigens noted above, these observations suggest that there is a reorganization of the vascular basement membrane in PS1 FAD-mutant mice.
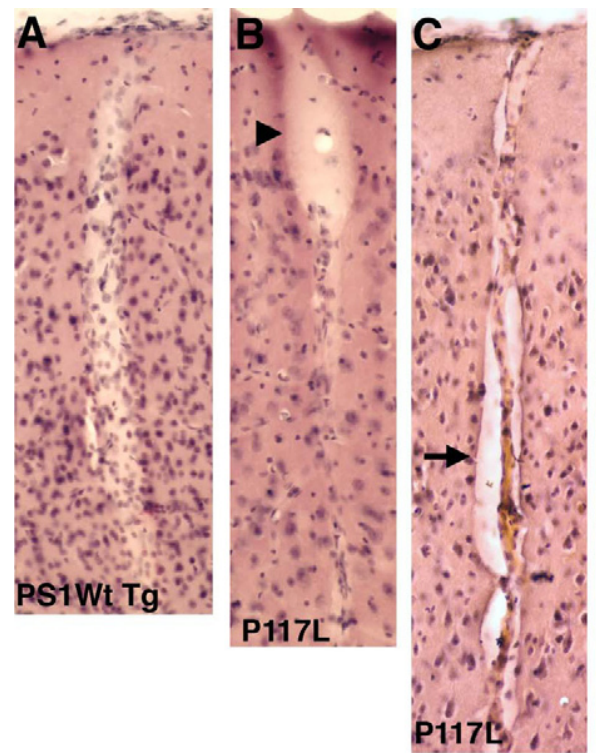
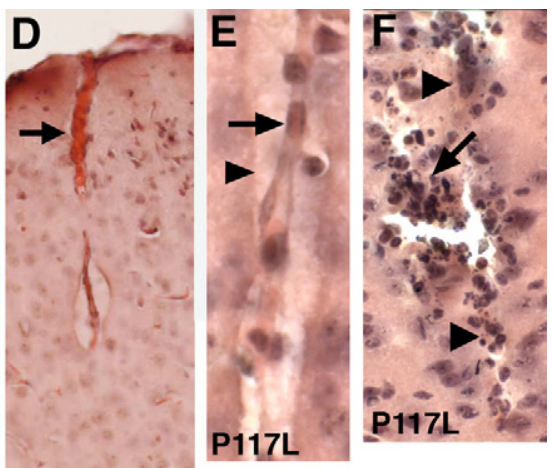

Figure 9. Histological abnormalities in penetrating cortical vessels in PS1 FAD-mutant mice Shown are H\&E-stained sections from NSE-PS1 wild-type transgenic (A) or NSE-P117L FAD mutant (B-F) mice. B: An abnormally expanded perivascular space at the cortical surface is indicated by the arrowhead. Microvessels in $\mathbf{C}$ and $\mathbf{D}$ have abnormally expanded perivascular spaces and a "vessel within a vessel" or "doublebarreled" appearance with the vessel in $\mathbf{D}$ containing a thrombus (arrow). E: A higher power view of a double-barreled vessel with the internal cord indicated by an arrow and the outer vessel wall by an arrowhead. F: A vessel with evidence of prior hemorrhage. The outlines of the vessel are indicated by arrowheads. An arrow indicates an area of infiltration of hemosiderin-laden mononuclear cells and polymorphonuclear leukocytes. Scale bar: $50 \mu \mathrm{m}, \mathbf{A}-\mathbf{D}$ $25 \mu \mathrm{m}, \mathbf{E}$ and $\mathbf{F}$. 

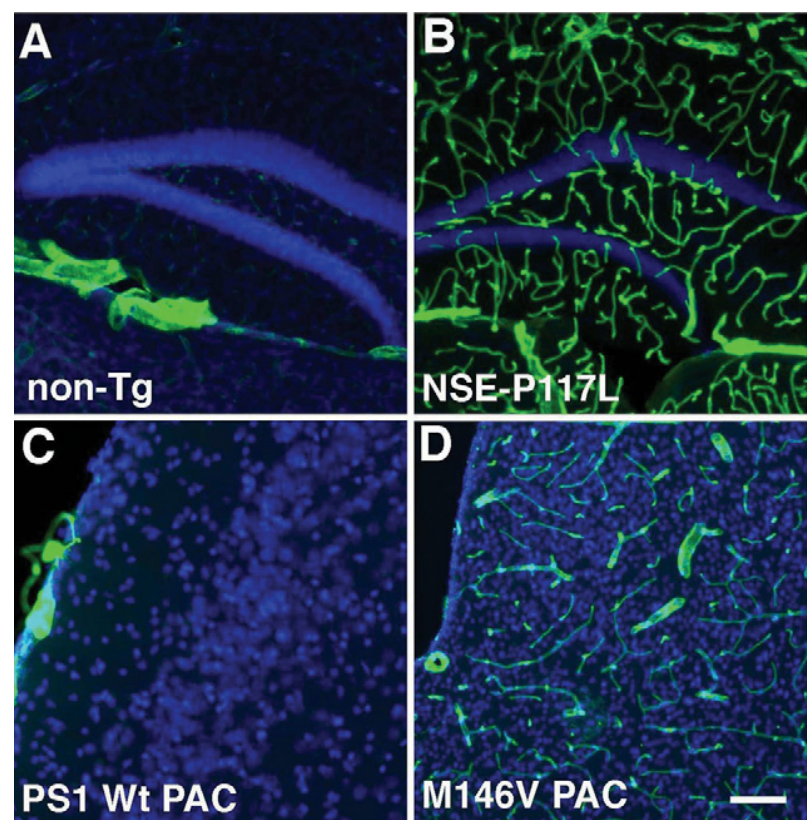

Figure 10. Abnormal vascular staining of collagen IV in PS1 FAD-mutant mice stained without pepsin pretreatment. Shown is collagen IV immunostaining (green) of the hippocampus (A and $\mathbf{B})$ or entorhinal cortex (C and D) of 15-month-old nontransgenic (A) or NSE-P117L (B), as well as 10month-old PS1 wild-type PAC (C) or M146V PAC (D) transgenic mice. Sections are counterstained with a nuclear stain (4',6-diamidino-2-phenylindole, blue). Note the prominent labeling of the vasculature in the FADmutant transgenic mice (B and D). Scale bar: $100 \mu \mathrm{m}$.

\section{Ultrastructural Analysis of Microvascular Pathology in PS1 FAD-Mutant Transgenic Mice}

To determine whether the immunostaining findings described above reflect alterations of the vascular basal laminae, we examined the microvasculature in the cerebral cortex of PS1 FAD-mutant transgenic mice by electron microscopy (EM). Figure 13 shows microvessels from the brains of 10- to 11-month-old PS1 PAC M146V or NSE-P117L FAD-mutant transgenic mice as well as from a non-transgenic littermate control or a mouse with the PS1 PAC wild-type transgene bred onto the PS1 $1^{-1-}$ background. Microvessels in the non-transgenic and human PS1 wild-type transgenic exhibited classic neurovascular ultrastructure with circular lumens, intact endothelial cells and smooth capillary walls (Figure 13, A and B). Despite the fact that vascular alterations at the light level are typically not apparent in 10-11 month old mice, many abnormal vascular profiles were apparent in both FAD-mutant lines (Figure 13, C-F). Luminal circularity was frequently lost and there were varying degrees of degeneration of the capillary wall. In addition, endothelial cell nuclei were distorted and swollen with in some cases white halos apparent around the nuclei (Figure 13, E and F).

By light microscopy, string vessels typically appear as abnormal connecting vessels between larger vessels that may extent for $30 \mu \mathrm{m}$ or more between vessels (Figure 3 ). To our knowledge there have been no descriptions of the ultrastructural correlates of string vessels. We searched for vascular profiles that might represent string vessels. Despite the relative rarity of string vessels, we were able to observe several profiles that may represent early
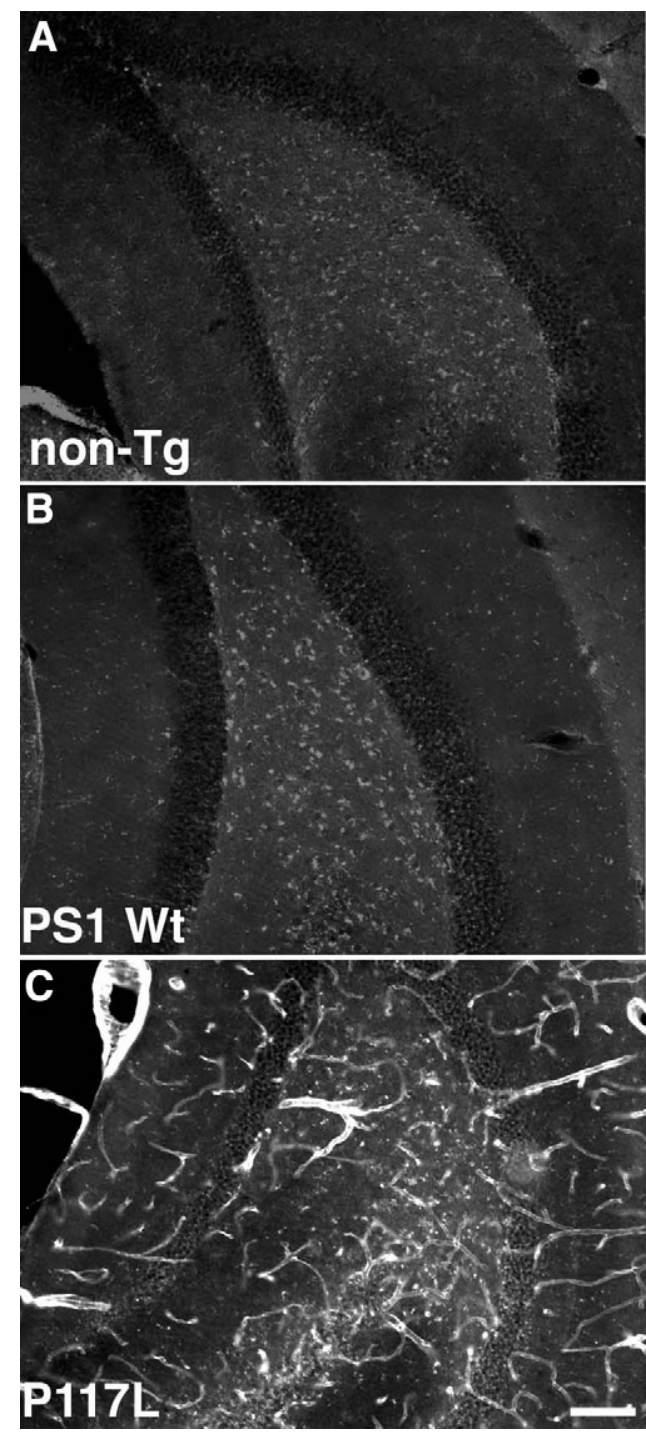

Figure 11. Abnormal vascular staining with perlecan in PS1 FAD-mutan mice stained without pepsin pretreatment. Anti-perlecan immunostaining is shown in the hippocampus from a 15-month-old nontransgenic (A), NSE-PS1 wild-type (B), and NSE-P117L transgenic $(\mathbf{C})$. Note the prominent vascular staining in the NSE-P117L transgenic animal (C). Scale bar: $100 \mu \mathrm{m}$.

stages of string vessel formation (Figure 14). In two of the three examples in Figure 14, abnormal bridging structures can be seen between microvessels. In one, two transversely sectioned microvessels are shown connected by a dysmorphic process containing two endothelial cell nuclei (Figure 14A), whereas in another (Figure $14 \mathrm{~B}$ ) a relatively normal appearing microvessel is connected to a degenerated microvessel by a short bridge. Other longitudinally cut microvessels could be seen that contained degenerative strictures (Figure 14C) that may also represent early stages of string vessels.

The altered immunostaining of microvessels in PS1 FAD-mutant animals with basement membrane-associated proteins shown above is also suggestive of an altered vascular basement membrane and indeed thickening and disruption of the vascular basal lamina was apparent in both lines. An example of basal lamina thickening from the NSEP117L line is illustrated in Figure 15. Interestingly, despite 


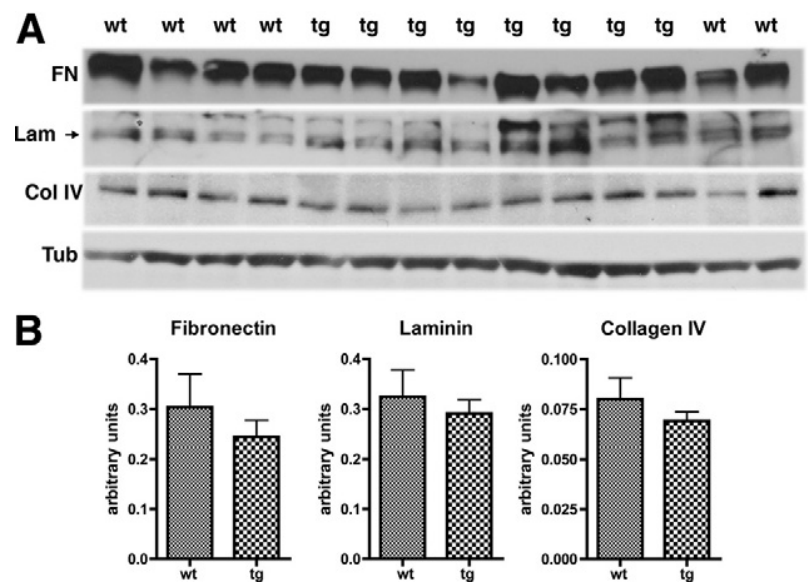

Figure 12. Unaltered levels of extracellular matrix-related proteins in brain homogenates of PS1 FAD-mutant mice. A: Levels of fibronectin (FN), laminin (Lam), and collagen IV (Col IV) were determined by Western blotting in extracts from the cerebral hemispheres of 19- to 26-month-old NSE-P117L FAD-mutant mice (tg, $n=8$ ) and their nontransgenic littermate controls (wt, $n=6$ ). Average ages of the transgenic ( $24.8 \pm 0.74$ months) and nontransgenic controls $(24.0 \pm 0.73$ months $)$ did not differ $(P=0.74$, unpaired $t$-test $)$. The arrow in the laminin panel indicates the $\sim 200 \mathrm{kDa}$ form. Blotting for fibronectin and laminin was performed sequentially on the same blot, followed by probing for $\beta$-tubulin as a loading control. As the samples for collagen IV quantification could not be boiled, these samples were electrophoresed separately and reprobed with $\beta$-tubulin. The $\beta$-tubulin panel shown is that which was used for fibronectin and laminin normalization. B: Quantification of the blots in $\mathbf{A}$ is shown with results normalized to the levels of $\beta$-tubulin (tub). There were no statistically significant differences between the groups (unpaired $t$-tests).

the obvious microvascular pathology, the surrounding neuropil appeared intact (Figures 13-15).

\section{Neuronal Expression of the FAD-Mutant Transgenes}

The pathology in the NSE-P117L is intriguing since the NSE transgene does not appear to be expressed in nonneuronal cells. Evidence for this is derived from our previous in situ hybridization studies where we observed a neuronal specific expression pattern of the NSE-driven transgenes. ${ }^{14}$ We have also examined PS1 expression in adult brain of the human PS1 PAC transgenic mice. Although hybridization with a human specific cRNA probe revealed widespread neuronal expression, we observed no expression in or around brain blood vessels (Figure 16). In addition, even if we relaxed the hybridization conditions so that the human probe cross-reacts with the endogenous mouse PS1, we still found no vascular hybridization (data not shown). These in situ findings on the expression of mouse PS1 are consistent with most other studies on the localization of PS1 in normal adult brain, which have reported an essentially neuronal specific expression pattern with no detectable expression in nonneuronal cells. ${ }^{29,39-41}$

These studies thus suggest that limited neuronal expression of a PS1 FAD mutant may be sufficient to induce vascular pathology. One prediction of this model is that pathology should not occur in microvessels located in regions such as white matter where transgene expression does not occur. As expected, the white matter ves-
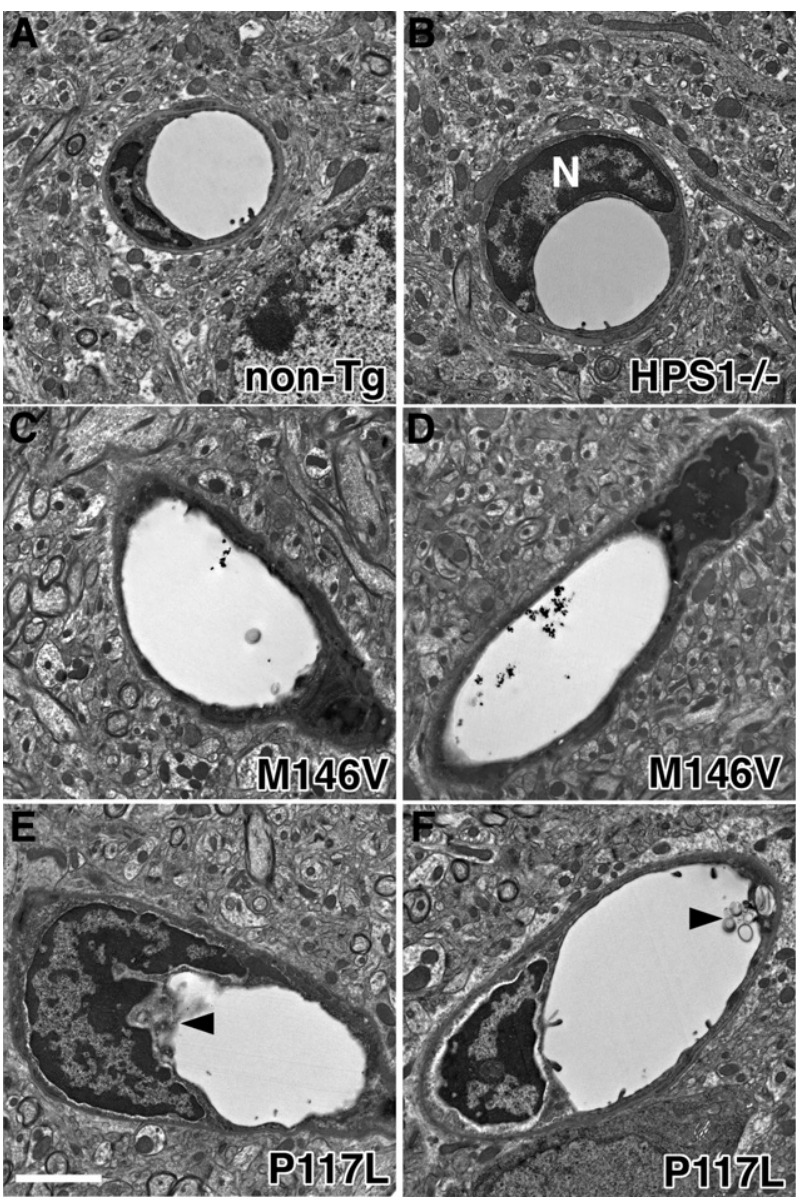

Figure 13. Ultrastructural analysis of cerebrovascular pathology in 10- to 11-month-old PS1 FAD-mutant transgenic mice. Transversely sectioned capillaries are shown from the prefrontal cortex of a nontransgenic littermate control (A), a mouse with the PS1 PAC wild-type transgene bred onto the $\mathrm{PS}^{-/-}$background (B), a PS1 PAC M146V FAD mutant (C and D), or a NSE-P117L FAD mutant (E and $\mathbf{F})$. The microvessels in $\mathbf{A}$ and $\mathbf{B}$ exhibit circular lumens, intact endothelial cells, and smooth capillary walls. An endothelial cell nucleus (N) is indicated in $\mathbf{B}$. C and $\mathbf{D}$ : Note the distortions of luminal circularity and the altered endothelial cell nuclei that appear both distorted and swollen. Note the halo formation surrounding the endothelial nuclei in $\mathbf{E}$ and $\mathbf{F}$. There were also varying degrees of degeneration of the capillary walls with amorphous material present in the capillary lumens (arrowheads in $\mathbf{E}$ and $\mathbf{F}$ ). The surrounding neurophil appears intact. Scale bar: $2 \mu \mathrm{m}$.

sels did not show pathology in either PS1 PAC M146V or NSE-P117L FAD-mutant transgenic mice. In Figure 17, examples of white matter vessels in the corpus callosum of a two-year-old PS1 PAC M146V transgenic mouse are shown. In the white matter, the microvessels appeared normal in contrast to the dysmorphic vessels seen in the adjacent hippocampus. Microvessels in the white matter of NSE-P117L FAD-mutant mice also appeared normal (data not shown). Collectively, these observations suggest that PS1 FAD mutants disrupt neuronal to vascular signaling in the adult brain. They also suggest that vascular remodeling in white matter may be controlled by distinct regulatory mechanisms that do not involve PS1.

\section{Discussion}

Vascular pathology is a consistent feature of AD. Here we show that two lines of PS1 FAD-mutant transgenic mice 

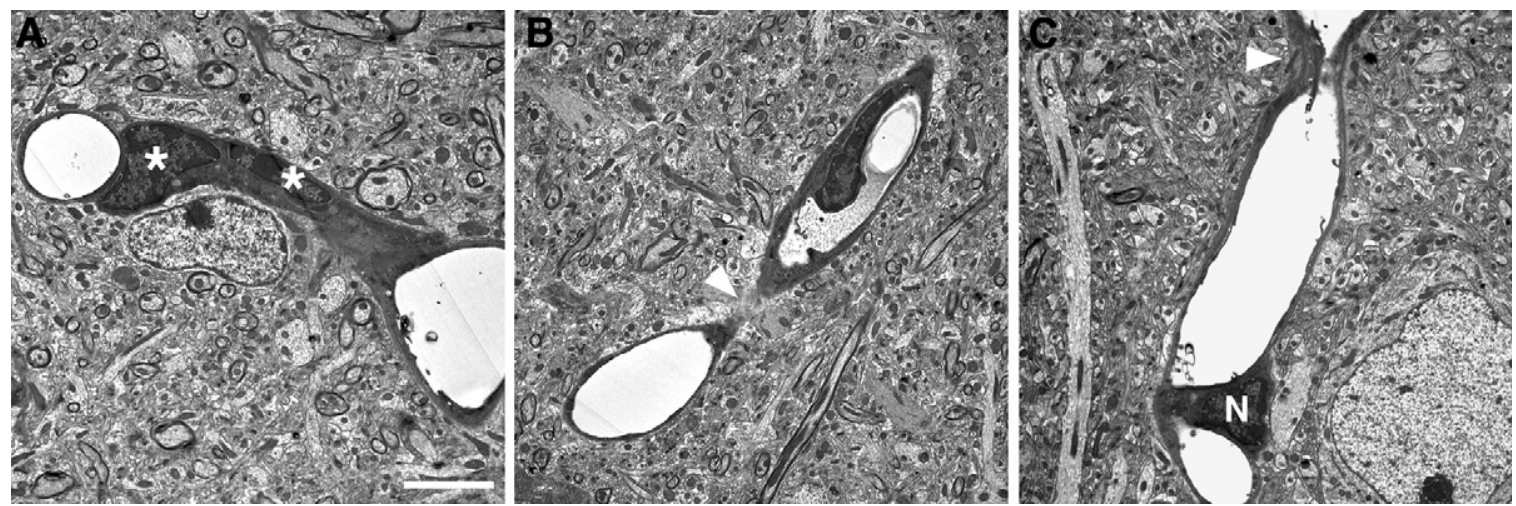

Figure 14. Abnormal vascular profiles in PS1 FAD-mutant transgenic mice. Shown are microvessels from the prefrontal cortex of the M146V FAD-mutant mouse shown in Figure 13. A: Two transversely sectioned microvessels are seen connected by a dysmorphic process containing two endothelial cell nuclei (indicated by asterisks). B: A relatively normal appearing microvessel at the bottom of the image is connected to a very dysmorphic microvessel by a short bridge (indicated by an arrowhead) that may represent a primitive string vessel. C: A longitudinally cut microvessel is shown that contains a degenerated segment with a stricture (indicated by an arrowhead). A dysmorphic endothelial cell nucleus (N) is indicated. The surrounding neuropil in each panel appears intact. Scale bar: $4 \mu \mathrm{m}$ in $\mathbf{A}$ and $\mathbf{C} ; 3 \mu \mathrm{m}$ in $\mathbf{B}$

develop a vascular pathology that shares features of the vascular pathology in AD. Although vascular pathology has been described in other AD transgenic models that overexpress FAD mutations associated with APP or combinations of APP with PS1 or PS2 FAD mutations, ${ }^{7-12}$ this report is to our knowledge the first description of vascular pathology in mice expressing PS FAD mutations alone.

Several features of the pathology merit comment. First, the pathology is not congophilic. CAA is the most recognized vascular pathology in $A D$, and although its severity can be highly variable, CAA is present to some degree in nearly all autopsied cases ${ }^{3}$ and is likewise present in human PS1 FAD cases to varying degrees. ${ }^{2}$ The lack of congophilia could be interpreted to suggest that vascular pathology in PS1 FAD-mutant mice may not be related to altered amyloid production. However, it could also suggest that soluble $A \beta$ oligomers ${ }^{42}$ may be toxic to blood vessels in addition to $A \beta$ deposits. Whereas PS FADmutant mice do not develop amyloid plaques, they do consistently exhibit altered $A \beta$ production. Indeed, the NSE-P117L line studied here has been previously shown to have high $A \beta 42$ levels $^{13}$ and the M146V FAD mutation consistently exhibits elevated $A \beta 42$ in both fibroblasts from human FAD patients, ${ }^{43}$ as well as in transgenic mice. ${ }^{32}$ Soluble monomers and oligomers are also more difficult to detect by immunohistochemical methods. Thus, it remains possible that soluble or oligomeric forms that cannot be detected by immunohistochemical methods and do not lead to frank amyloid deposits are nevertheless driving the pathology. Interestingly, KumarSingh et $\mathrm{al}^{7}$ have reported that pathological changes can be found in both amyloid-laden and nonamyloidotic microvessels in Tg2576 and PS/APP mice, suggesting that even in the setting of frank CAA, vascular pathology still occurs in non-affected vessels. The present study can thus be seen as either further support for the $A \beta$ oligomer hypothesis or as a challenge to the amyloid hypothesis itself. Additional studies are needed to determine whether oligomeric forms of $A \beta$ deposits within these vessels.

A second notable feature of the pathology is that alterations in the vascular basement membranes occur early in PS1 FAD-mutant vessels. Vascular membrane alterations are also characteristic of the microangiopathy in AD. ${ }^{36}$ Ultrastructurally, the capillary basement membranes appeared thickened and dystrophic in PS1 FADmutant mice before other morphological manifestations of vascular pathology were evident. The basement membrane is a complex mixture of extracellular matrix proteins, proteoglycans, and structural proteins. Despite
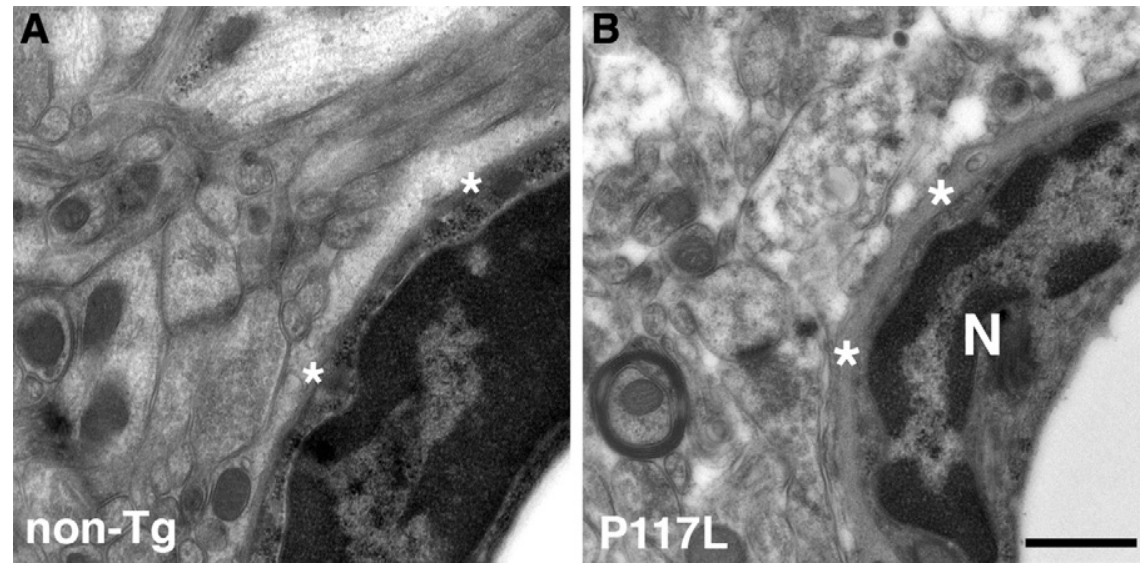

Figure 15. Thickening of the vascular basal lamina in NSE-P117L FAD-mutant transgenic mice. Transversely sectioned microvessels are shown from the prefrontal cortex of a nontransgenic littermate control (A) and an NSE-P117L FAD mutant (B). The basal laminae are indicated by asterisks in both panels. Note the thickened appearance of the basal lamina in the P117L FAD mutant as well as the altered chromatin structure in the nucleus (N) of the endothelial cell. Similar observations were made in the PS1 PAC M146V FAD mutant. Scale bar: $500 \mathrm{~nm}$. 

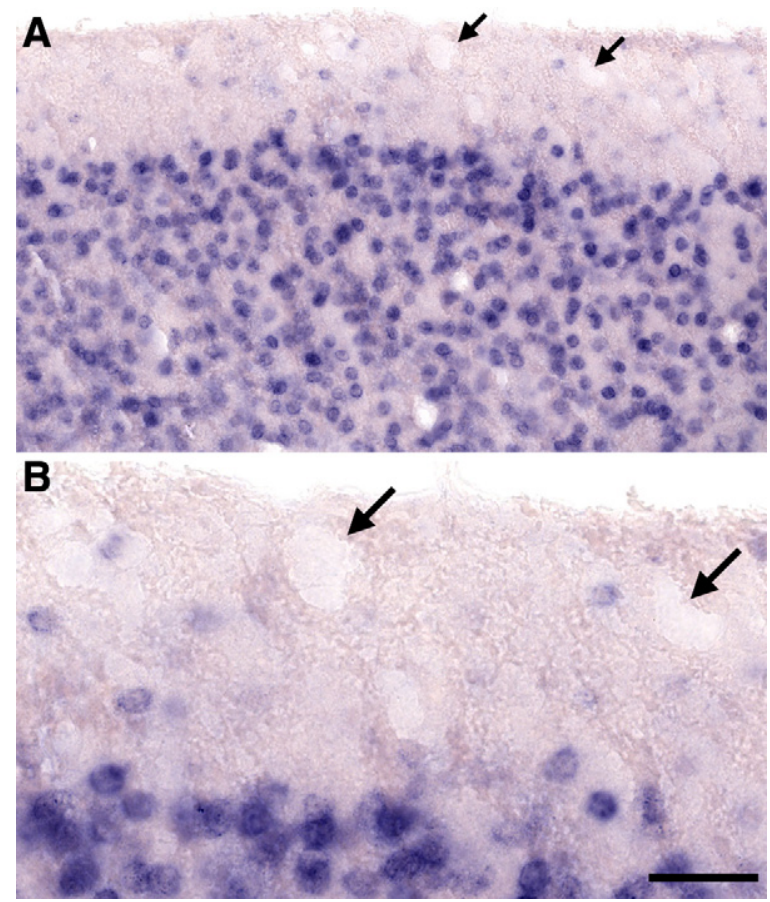

Figure 16. Lack of transgene expression in blood vessels of PS1 PAC transgenic mice. In situ hybridization was performed with a human-specific PS1 antisense cRNA probe. An example is shown of hybridization along the cortical surface in a PS1 PAC wild-type transgenic mouse. Note the strong hybridization in cells in the deeper cortical layers and the lack of hybridization in the microvessels in layer I, two of which are indicated by an arrow Scale bar: $50 \mu \mathrm{m}, \mathbf{A} ; 25 \mu \mathrm{m}, \mathbf{B}$

their presence in normal adult mouse brain, staining for many basement membrane antigens, including collagen IV, occurs only inconsistently in standard perfusion-fixed tissues unless an antigen retrieval method is used. ${ }^{20}$ Interestingly however, vascular staining occurred in the brains of PS1 FAD-mutant mice when using collagen IV as well as perlecan antisera even without pepsin digestion.

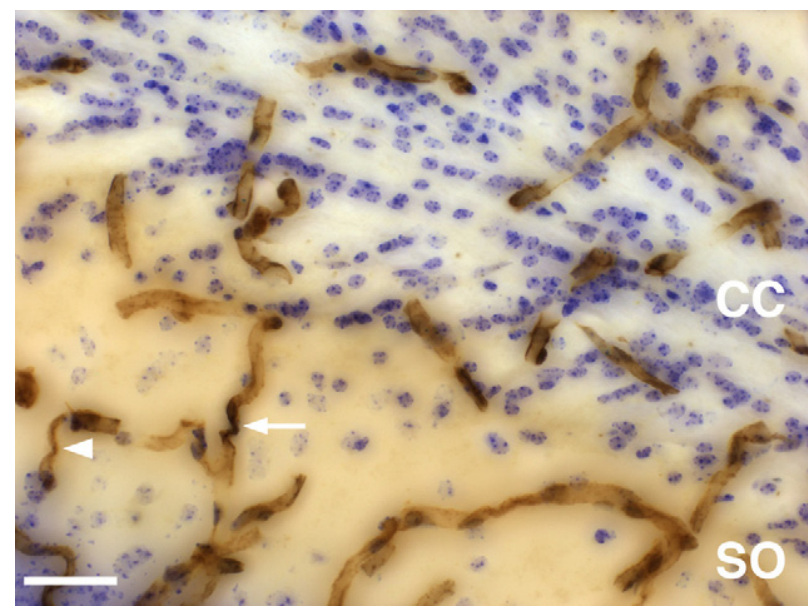

Figure 17. Lack of microvascular pathology in white matter of PS1 FADmutant mice. Shown are anti-collagen IV immunoperoxidase-stained microvessels combined with a Nissl counterstain in a 2-year-old PS1 PAC M146V transgenic mouse. Note the normal vascular profiles in the corpus callosum (CC). In contrast, abnormal vascular profiles are apparent in the stratum oriens (SO) of the hippocampus. Within the stratum oriens, kinked (arrow) and thinned (arrowhead) microvessels are indicated. Scale bar: $50 \mu \mathrm{m}$.
Enhanced vascular staining could reflect increased production of extracellular matrix-related proteins. Thickening of the vascular basal lamina was observed by electron microscopy. However, we did not find any increase in levels of collagen IV, laminin, or fibronectin in the brains of NSE-P117L FAD mutants by Western blotting, arguing that there is no increase in expression of these extracellular matrix-related proteins and that, instead, the increased vascular staining likely represents a reorganization of the vascular extracellular matrix with increased accessibility of these antigens to immunostaining. Interestingly, staining of vessels with antigens such as collagen IV without pepsin treatment is also typical of immature vessels, ${ }^{20}$ and is also seen in vessels in areas of injured adult brain following mechanical trauma. ${ }^{44}$ Whereas the physiological basis for these differing patterns of staining are incompletely understood, they seem to correlate best with the tightness of the gliovascular junctions (reviewed in Ref. 20). Indeed, one major structural difference between immature (which stain well for these antigens without pepsin treatment) and mature microvessels in brain is the large perivascular spaces present in immature microvessels that separate the outer glial basal lamina and the inner vascular one. ${ }^{44,45}$ In fact, the tightness of the gliovascular junctions seems to correlate with the intensity of laminin immunostaining following mechanical injury. ${ }^{44}$ Thus, by analogy, an early feature of the pathology in FAD-mutant mice may be a loss of the normal tightness of the gliovascular junctions. Importantly, widened perivascular spaces and glial processes filled with amorphous material were observed in FAD-mutant mice at an age before prominent vascular pathology was apparent at the light microscopy level.

Altered vascular basement membranes and gliovascular junctions could be interpreted as increased vascular remodeling in PS1 FAD-mutant mice, perhaps stimulated as a response to oligomeric $A \beta$. Alternatively, altered trophic signaling could be stimulating vascular remodeling independent of $A \beta$ production. In this context, two important vasculotrophic factors, vascular endothelial growth factor and transforming growth factor $\beta 1$ have been reported to be increased in AD brain. ${ }^{46-49}$ It has also been recently reported that expression of $\alpha_{\mathrm{v}} \beta_{3}$ integrin, which is regarded as a marker of angiogenesis, is increased in microvessels of AD brain. ${ }^{50}$ This observation further supports the notion that active vascular remodeling is occurring in AD. Interestingly, transgenic mice expressing a constitutively active form of transforming growth factor $\beta 1$ have also been reported to develop CAA with an early feature of the pathology being thickening of the basement membranes. ${ }^{51} A \beta$ itself is cleared from brain both through receptor-mediated transport across endothelial cells as well as by interstitial transport through perivascular spaces. ${ }^{52,53}$ Whether induced by $A \beta$ or other factors, thickened vascular basement membranes with altered gliovascular junctions could in turn impair $A \beta$ transport and perhaps create a cycle in which further membrane remodeling leads to progressive pathology.

A third notable feature of the vascular pathology in PS1 FAD-mutant mice is that the pathophysiological 
basis for the vascular pathology appears to originate in neurons as in both lines, the FAD-mutant transgenes are expressed in neurons but not in glia or blood vessels. Our previous in situ hybridization studies have documented a neuron-specific expression pattern of the NSE-driven wild-type and P117L transgenes. ${ }^{14}$ In fact, whereas PS1 is expressed widely during development and in nonneural tissues in the adult, immunohistochemical studies of PS1 expression have generally found a neuronal expression pattern in adult brain without detectable expression in glial cells or vascular endothelial cells. ${ }^{29}$ PS1 is expressed in reactive astrocytes but is otherwise not readily detected in astrocytes in uninjured brain. ${ }^{54,55}$ Our in situ hybridization studies of PS1 PAC mice with a human-specific cRNA probe also revealed widespread neuronal expression, but no expression in or around brain blood vessels.

Altogether these lines of evidence suggest that the vascular pathology has a neuronal origin. This could argue for a neuronal origin of toxic oligomeric $A \beta$, and these studies in fact parallel other studies showing that CAA can be induced by mutant APP transgenes driven by the neuron-specific Thy 1 promoter. $^{8-10}$ Alternatively, these studies may suggest that PS1 influences neuronal signals that regulate vascular homeostasis in adult brain with FAD-mutant PS1 disturbing these signals. This also provides an interesting parallel to our studies showing that during development, selective expression of PS1 on the neuroepithelial side is sufficient to rescue vascular development in the PS1 null mutant, ${ }^{56}$ an effect that cannot be explained on the basis of $A \beta$ production. Indeed, based on the restricted expression of the PS1 FAD mutants to neurons one may postulate that the FAD mutant initially disrupts a neuronal-to-vascular signal that is required for normal vascular homeostasis. With time this could lead to a gradual age-related vascular compromise and with further aging, the vascular defect could compromise the integrity of the neurovascular unit until metabolic or trophic support of the neuron becomes affected leading to neuronal dysfunction.

Independent of what the mechanisms for the early alterations in the vascular basement membranes in PS1 FAD mutant might be, we show here that PS1 FAD mutant mice develop a microangiopathy that mimics many of the core features of the vascular pathology seen in $A D$ but without CAA. These studies have implications both for the form of $A \beta$ that may be crucial in producing vascular pathology and the role of neuronal to vascular signaling in the production of pathology. Future studies of these mice offer the opportunity to uncover the role of PS1 FAD mutants in neurovascular signaling and provide insights into how neurovascular signaling may be disrupted in sporadic $A D$ as well.

\section{Acknowledgments}

Transgenic mice were generated through the Mount Sinai School of Medicine Mouse Genetics Shared Resource Facility. TgCRND8 mice were a gift from Drs. David Westaway and Paul Fraser, and we thank Drs. Michelle Ehrlich and Sam Gandy as well as Ms. Loren Khan for maintaining the Mount Sinai colony. Drs. Paul Matthews and Nikolaos Robakis are thanked for gifts of antibodies and Drs Ali Imam and Frank Grosveld for providing plasmids. We thank Bridget Wicinski for expert technical assistance.

\section{References}

1. Ertekin-Taner N: Genetics of Alzheimer's disease: a centennial review. Neurol Clin 2007, 25:611-667

2. Lleo A, Berezovska O, Growdon JH, Hyman BT: Clinical, pathological and biochemical spectrum of Alzheimer disease associated with PS-1 mutations. Am J Geriatr Psychiatry 2004, 12:146-156

3. Kumar-Singh S: Cerebral amyloid angiopathy: pathogenetic mechanisms and link to dense amyloid plaques. Genes Brain Behav 2008, 7(Suppl)1:67-82

4. Revesz T, Ghiso J, Lashley T, Plant G, Rostagno A, Frangione B Holton JL: Cerebral amyloid angiopathies: a pathologic, biochemical, and genetic view. J Neuropathol Exp Neurol 2003, 62:885-898

5. Bailey TL, Rivara CB, Rocher AB, Hof PR: The nature and effects of cortical microvascular pathology in aging and Alzheimer's disease. Neurol Res 2004, 26:573-578

6. Buée L, Hof PR, Bouras C, Delacourte A, Perl DP, Morrison JH, Fillit $\mathrm{HM}$ : Pathological alterations of the cerebral microvasculature in Alzheimer's disease and related dementing disorders. Acta Neuropathol (Berl) 1994, 87:469-480

7. Kumar-Singh S, Pirici D, McGowan E, Serneels S, Ceuterick C, Hardy $J$, Duff K, Dickson D, Van Broeckhoven C: Dense-core plaques in Tg2576 and PSAPP mouse models of Alzheimer's disease are centered on vessel walls. Am J Pathol 2005, 167:527-543

8. Van Dorpe J, Smeijers L, Dewachter I, Nuyens D, Spittaels K, Van Den Haute C, Mercken M, Moechars D, Laenen I, Kuiperi C, Bruynseels K, Tesseur I, Loos R, Vanderstichele H, Checler F, Sciot R, Van Leuven $\mathrm{F}$ : Prominent cerebral amyloid angiopathy in transgenic mice overexpressing the London mutant of human APP in neurons. Am J Pathol 2000, 157:1283-1298

9. Calhoun ME, Burgermeister $P$, Phinney AL, Stalder M, Tolnay M, Wiederhold KH, Abramowski D, Sturchler-Pierrat C, Sommer B, Staufenbiel M, Jucker M: Neuronal overexpression of mutant amyloid precursor protein results in prominent deposition of cerebrovascular amyloid. Proc Natl Acad Sci USA: 1999, 96:14088-14093

10. Herzig MC, Winkler DT, Burgermeister P, Pfeifer M, Kohler E, Schmidt SD, Danner S, Abramowski D, Sturchler-Pierrat C, Burki K, van Duinen SG, Maat-Schieman ML, Staufenbiel M, Mathews PM, Jucker M: $A \beta$ is targeted to the vasculature in a mouse model of hereditary cerebral hemorrhage with amyloidosis. Nat Neurosci 2004, 7:954-960

11. Tong XK, Nicolakakis N, Kocharyan A, Hamel E: Vascular remodeling versus amyloid $\beta$-induced oxidative stress in the cerebrovascular dysfunctions associated with Alzheimer's disease. J Neurosci 2005, 25:11165-11174

12. Lopez-Lopez C, Dietrich MO, Metzger F, Loetscher H, Torres-Aleman I: Disturbed cross-talk between insulin-like growth factor I and AMPactivated protein kinase as a possible cause of vascular dysfunction in the amyloid precursor protein/presenilin 2 mouse model of Alzheimer's disease. J Neurosci 2007, 27:824-831

13. Wen PH, Hof PR, Chen X, Gluck K, Austin G, Younkin SG, Younkin LH, DeGasperi R, Gama Sosa MA, Robakis NK, Haroutunian V, Elder GA: The presenilin-1 familial Alzheimer disease mutant P117L impairs neurogenesis in the hippocampus of adult mice. Exp Neurol 2004, 188:224-237

14. Wen PH, Shao X, Shao Z, Hof PR, Wisniewski T, Kelley K, Friedrich VL Jr, Ho L, Pasinetti GM, Shioi J, Robakis NK, Elder GA: Overexpression of wild type but not an FAD mutant Presenilin-1 promotes neurogenesis in the hippocampus of adult mice. Neurobiol Dis 2002, 10:8-19

15. Rogaev El, Sherrington R, Wu C, Levesque G, Liang Y, Rogaeva EA, Ikeda M, Holman K, Lin C, Lukiw WJ, de Jong PJ, Fraser PE, Rommens JM, St George-Hyslop P: Analysis of the 5' sequence, genomic structure, and alternative splicing of the presenilin-1 gene (PSEN1) associated with early onset Alzheimer disease. Genomics 1997, 40:415-424

16. Gama Sosa MA, DeGasperi R, Gonzalez EA, Kelley K, Lazzarini R, 
Elder GA: BAC and PAC DNA for the generation of transgenic animals. Biotechniques 2002, 33:51-53

17. Ali Imam AM, Patrinos GP, de Krom M, Bottardi S, Janssens RJ, Katsantoni E, Wai AWK, Sherrat DJ, Grosveld FG: Modification of human $\beta$-globin locus PAC clones by homologous recombination in Escherichia coli. Nucleic Acids Res 2000, 28:e65

18. Shen J, Bronson RT, Chen DF, Xia W, Selkoe DJ, Tonegawa S: Skeletal and CNS defects in Presenilin-1-deficient mice. Cell 1997, 89:629-639

19. Schmidt ML, Robinson KA, Lee VM, Trojanowski JQ: Chemical and immunological heterogeneity of fibrillar amyloid in plaques of Alzheimer's disease and Down's syndrome brains revealed by confocal microscopy. Am J Pathol 1995, 147:503-515

20. Franciosi S, De Gasperi R, Dickstein DL, English DF, Rocher AB, Janssen WG, Christoffel D, Sosa MA, Hof PR, Buxbaum JD, Elder GA: Pepsin pretreatment allows collagen IV immunostaining of blood vessels in adult mouse brain. J Neurosci Methods 2007, 163:76-82

21. Calhoun ME, Mouton PR: Length measurement: new developments in neurostereology and 3D imagery. J Chem Neuroanat 2001, 21:257-265

22. Kreczmanski P, Schmidt-Kastner R, Heinsen H, Steinbusch HW, Hof PR Schmitz C: Stereological studies of capillary length density in the frontal cortex of schizophrenics. Acta Neuropathol (Berl) 2005, 109:510-518

23. Mouton PR, Gokhale AM, Ward NL, West MJ: Stereological length estimation using spherical probes. J Microsc 2002, 206:54-64

24. Schmitz C, Hof PR: Design-based stereology in neuroscience. Neuroscience 2005, 130:813-831

25. Janssen WG, Vissavaijhala P, Andrews G, Moran T, Hof PR, Morrison $\mathrm{JH}$ : Cellular and synaptic distribution of NR2A and NR2B in macaque monkey and rat hippocampus as visualized with subunit-specific monoclonal antibodies. Exp Neurol 2005, 191(Suppl 1):S28-S44

26. Chaudhry FA, Lehre KP, van Lookeren Campagne M, Ottersen OP, Danbolt NC, Storm-Mathisen J: Glutamate transporters in glial plasma membranes: highly differentiated localizations revealed by quantitative ultrastructural immunocytochemistry. Neuron 1995, 15:711-720

27. Hjelle OP, Chaudhry FA, Ottersen OP: Antisera to glutathione: characterization and immunocytochemical application to the rat cerebellum. Eur J Neurosci 1994, 6:793-804

28. van Lookeren Campagne M, Oestreicher AB, van der Krift TP, Gispen WH, Verkleij AJ: Freeze-substitution and Lowicryl HM20 embedding of fixed rat brain: suitability for immunogold ultrastructural localization of neural antigens. J Histochem Cytochem 1991, 39:1267-1279

29. Elder GA, Tezapsidis N, Carter J, Shioi J, Bouras C, Li H-C, Johnston JM, Efthimiopoulos S, Friedrich VL, Robakis NK: Identification and neuron specific expression of the S182/presenilin I protein in human and rodent brains. J Neurosci Res 1996, 45:308-320

30. Qian S, Jiang P, Guan XM, Singh G, Trumbauer ME, Yu H, Chen HY, Van de Ploeg LH, Zheng $\mathrm{H}$ : Mutant human presenilin 1 protects presenilin 1 null mouse against embryonic lethality and elevates A $\beta 1-42 / 43$ expression. Neuron 1998, 20:611-617

31. Davis JA, Naruse S, Chen H, Eckman C, Younkin S, Price DL, Borchelt DR, Sisodia SS, Wong PC: An Alzheimer's disease-linked PS1 variant rescues the developmental abnormalities of PS1-deficient embryos. Neuron 1998, 20:603-609

32. Duff K, Eckman C, Zehr C, Yu X, Prada CM, Perez-tur J, Hutton M, Buee L, Harigaya Y, Yager D, Morgan D, Gordon MN, Holcomb L, Refolo L, Zenk B, Hardy J, Younkin S: Increased amyloid- $\beta 42(43)$ in brains of mice expressing mutant presenilin 1. Nature 1996, 383:710-713

33. Chishti MA, Yang DS, Janus C, Phinney AL, Horne P, Pearson J, Strome R, Zuker N, Loukides J, French J, Turner S, Lozza G, Grilli M, Kunicki S, Morissette C, Paquette J, Gervais F, Bergeron C, Fraser PE, Carlson GA, George-Hyslop PS, Westaway D: Early-onset amyloid deposition and cognitive deficits in transgenic mice expressing a double mutant form of amyloid precursor protein 695. J Biol Chem 2001, 276:21562-21570

34. Mandybur TI: Cerebral amyloid angiopathy: the vascular pathology and complications. J Neuropathol Exp Neurol 1986, 45:79-90

35. Vinters HV: Cerebral amyloid angiopathy: a critical review. Stroke 1987, 18:311-324

36. Zarow C, Barron E, Chui HC, Perlmutter LS: Vascular basement membrane pathology and Alzheimer's disease. Ann NY Acad Sci 1997, 826:147-160
37. Jucker M, Bialobok P, Hagg T, Ingram DK: Laminin immunohistochemistry in brain is dependent on method of tissue fixation. Brain Res 1992, 586:166-170

38. Mori S, Sternberger NH, Herman MM, Sternberger LA: Variability of laminin immunoreactivity in human autopsy brain. Histochemistry 1992, 97:237-241

39. Busciglio J, Hartmann H, Lorenzo A, Wong C, Baumann K, Sommer B, Staufenbiel M, Yankner BA: Neuronal localization of presenilin-1 and association with amyloid plaques and neurofibrillary tangles in Alzheimer's disease. J Neurosci 1997, 17:5101-5107

40. Cribbs DH, Chen LS, Bende SM, LaFerla FM: Widespread neuronal expression of the presenilin-1 early-onset Alzheimer's disease gene in the murine brain. Am J Pathol 1996, 148:1797-1806

41. Lee MK, Slunt HH, Martin LJ, Thinakaran G, Kim G, Gandy SE, Seeger M, Koo E, Price DL, Sisodia SS: Expression of presenilin 1 and 2 (PS1 and PS2) in human and murine tissues. J Neurosci 1996, 16:7513-7525

42. Walsh DM, Selkoe DJ: A $\beta$ oligomers-a decade of discovery. J Neurochem 2007, 101:1172-1184

43. Scheuner D, Eckman C, Jensen M, Song X, Citron M, Suzuki N, Bird TD, Hardy J, Hutton M, Kukull W, Larson E, Levy-Lahad E, Viitanen M, Peskind E, Poorkaj P, Schellenberg G, Tanzi R, Wasco W, Lannfelt L, Selkoe D, Younkin S: Secreted amyloid $\beta$-protein similar to that in the senile plaques of Alzheimer's disease is increased in vivo by the presenilin 1 and 2 and APP mutations linked to familial Alzheimer's disease. Nat Med 1996, 2:864-870

44. Szabo A, Kalman M: Disappearance of the post-lesional laminin immunopositivity of brain vessels is parallel with the formation of gliovascular junctions and common basal lamina: a double-labelling immunohistochemical study. Neuropathol Appl Neurobiol 2004, 30:169-177

45. Caley DW, Maxwell DS: Development of the blood vessels and extracellular spaces during postnatal maturation of rat cerebral cortex. J Comp Neurol 1970, 138:31-47

46. Chiappelli M, Borroni B, Archetti S, Calabrese E, Corsi MM, Franceschi M, Padovani A, Licastro F: VEGF gene and phenotype relation with Alzheimer's disease and mild cognitive impairment. Rejuvenation Res 2006, 9:485-493

47. Thirumangalakudi L, Samany PG, Owoso A, Wiskar B, Grammas P: Angiogenic proteins are expressed by brain blood vessels in Alzheimer's disease. J Alzheimers Dis 2006, 10:111-118

48. Tarkowski E, Issa R, Sjogren M, Wallin A, Blennow K, Tarkowski A, Kumar P: Increased intrathecal levels of the angiogenic factors VEGF and TGF- $\beta$ in Alzheimer's disease and vascular dementia. Neurobiol Aging 2002, 23:237-243

49. Grammas $P$, Ovase R: Cerebrovascular transforming growth factor- $\beta$ contributes to inflammation in the Alzheimer's disease brain. Am J Pathol 2002, 160:1583-1587

50. Desai BS, Schneider JA, Li JL, Carvey PM, Hendey B: Evidence of angiogenic vessels in Alzheimer's disease. J Neural Transm 2009, 116:587-597

51. Wyss-Coray T, Lin C, Sanan DA, Mucke L, Masliah E: Chronic overproduction of transforming growth factor- $\beta 1$ by astrocytes promotes Alzheimer's disease-like microvascular degeneration in transgenic mice. Am J Pathol 2000, 156:139-150

52. Weller RO, Massey A, Newman TA, Hutchings M, Kuo YM, Roher AE: Cerebral amyloid angiopathy: amyloid $\beta$ accumulates in putative interstitial fluid drainage pathways in Alzheimer's disease. Am J Pathol 1998, 153:725-733

53. Zlokovic BV: The blood-brain barrier in health and chronic neurodegenerative disorders. Neuron 2008, 57:178-201

54. Cribbs DH, Chen LS, Cotman CW, LaFerla FM: Injury induces presenilin-1 gene expression in mouse brain. Neuroreport 1996, 7:1773-1776

55. Huynh DP, Vinters HV, Ho DH, Ho VV, Pulst SM: Neuronal expression and intracellular localization of presenilins in normal and Alzheimer disease brains. J Neuropathol Exp Neurol 1997, 56:1009-1017

56. Wen PH, De Gasperi R, Sosa MA, Rocher AB, Friedrich VL Jr, Hof PR, Elder GA: Selective expression of presenilin 1 in neural progenitor cells rescues the cerebral hemorrhages and cortical lamination defects in presenilin 1-null mutant mice. Development 2005 132:3873-3883 